\title{
UICLISSIFIED
}

Contract Ho, $w-7405$, eng. 26

ORu- 127

REACTORS - POWER

Subcontract 110. $25 \overline{7}$

Prices 5.3 .5

Avoilable from the Office of Technical Services Department of Commtree Washington 25, D.C.
CLASSIFICATION CANCELLED DATE MAR 121957 For The Atomic Enargy Commission - 18<smiles>[C]1CCCC1</smiles>
Chief, Deciaseification Branch

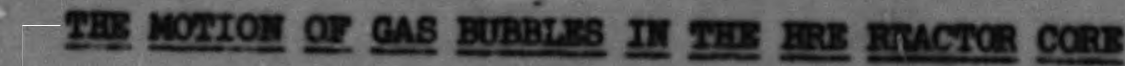

by

F. II. Peebles

The Univereity of Temnessee

Depertment of Chentcel Engineering

Date Issued: JAN 181952

OAK RIDEE WATIOALAL IABCRATCRY

Operated by

CARBIDS AMT CARBOI CHETCATS COARAT

A DIVISION OF UITON CARBIDS AID CARBOI CORPCRATOI

Oak R1dge, Tennessee

\section{DEGAL MOTICE}

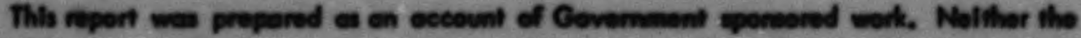

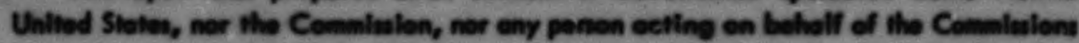

A. Makes any warranty or reprosentuilion, expesa er linplied, with napect to the ae-

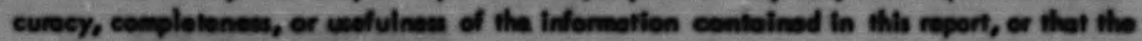
ue of any information, epporotus, nothod, or process diseloved in thls roport nay nat infringe privatoly owned rightsy or

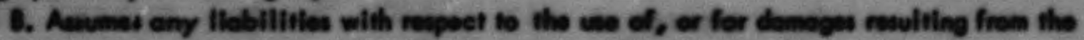
we of eny information, epparatus, enthed, or procese dliselosed in this ropert.

As uned in the above, "penon eeting on behalf of the Connialon" includes eny enployes or controctor of the Commistion to the extent that such employes or controcter

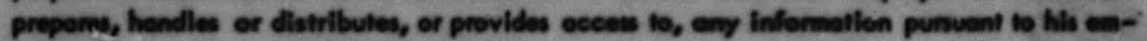
ployment or controct with the Conminalon. 


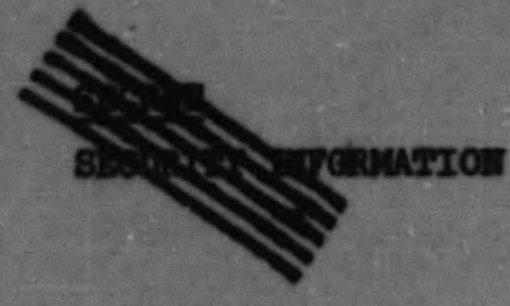

TABIS of COHMRIMS

$\gamma_{*}$

sUnocurY

IBIRODUCTIOH

DATA OII GAS BUBBLE MOTION AID VELOCTMIES

Theory

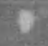

A Review of the Literature

Studies at the Untversity of Tennessee

Recomended Relations

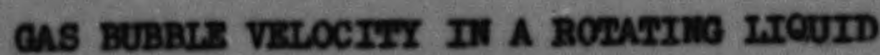

Development of Basic Iquations

Computation of Maxinum Gas Bubble Resiaence Time

TOTAL GAS BOLD-UP III THE HRE REACTOR CORE

DISCussion of THE Resurns

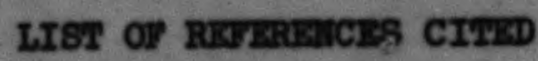

APPIIDIX

40

Table of Ilomenclature

42

Computation Procedure

44

\section{RESTRICTED DATA}

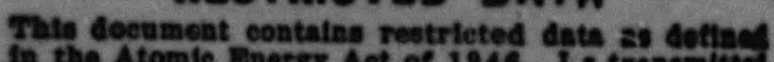

in the Atomic Energy Act of 1946 . Io tranomittil

or the disclosure of its contents in ony manner to 
$$
-5-
$$

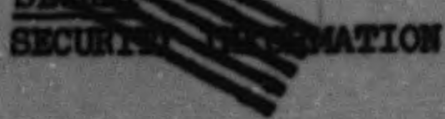

\section{CONFHOEMnL}

(3) A method for computing the steady state state ges hold-up In the $\mathrm{EB}$ reactor core under power producing conditions is presented. The results of conputations based on this method are presented. Such results indicate that 0.10 to 0.55 volume percent ges hold-up vill be realized in the IRE reactor core. These velues reflect the Influence of gas bubble e1ze over the range of 0.001 to 0.6 inch diameter and the influence of 11quid velocities in the reactor core corresponding to a 2 inch and a 1 1/2 inch nominal dianoter Inlet pipe.

It is concluded that the reletions and mothods presented are general in scope, and could be applied to any size reactor core providing basic date on 11quid velocity distribution, gas bubble size and physicel properties are known.

\section{IIIRODUCYIOW}

The removal of gas bubbles from the fuel solution by centripetel action resulting from rotary motion of the 11quid vithin the spherical BRE reactor core vas described in ORIL-630. As described in the report eited, 1t vas found that a stable liquid flow pattern could be maintained with 11quid being Introduced on a chord of the sphere. Under such conaltions the 11quid moved in an approximately spiral path toward the center of the sphere with the formation of a cylindricel gas vold aligned with

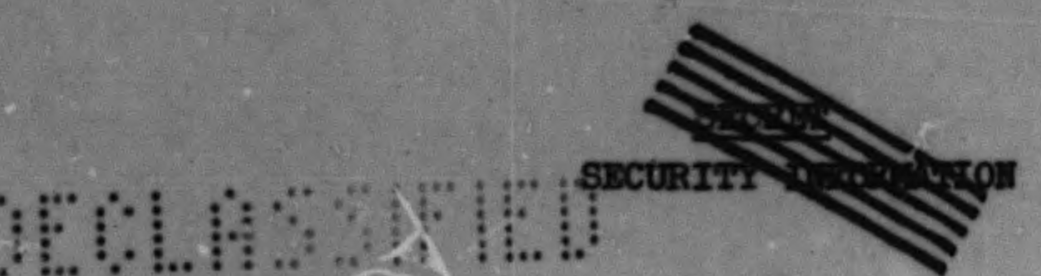

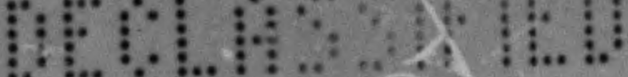





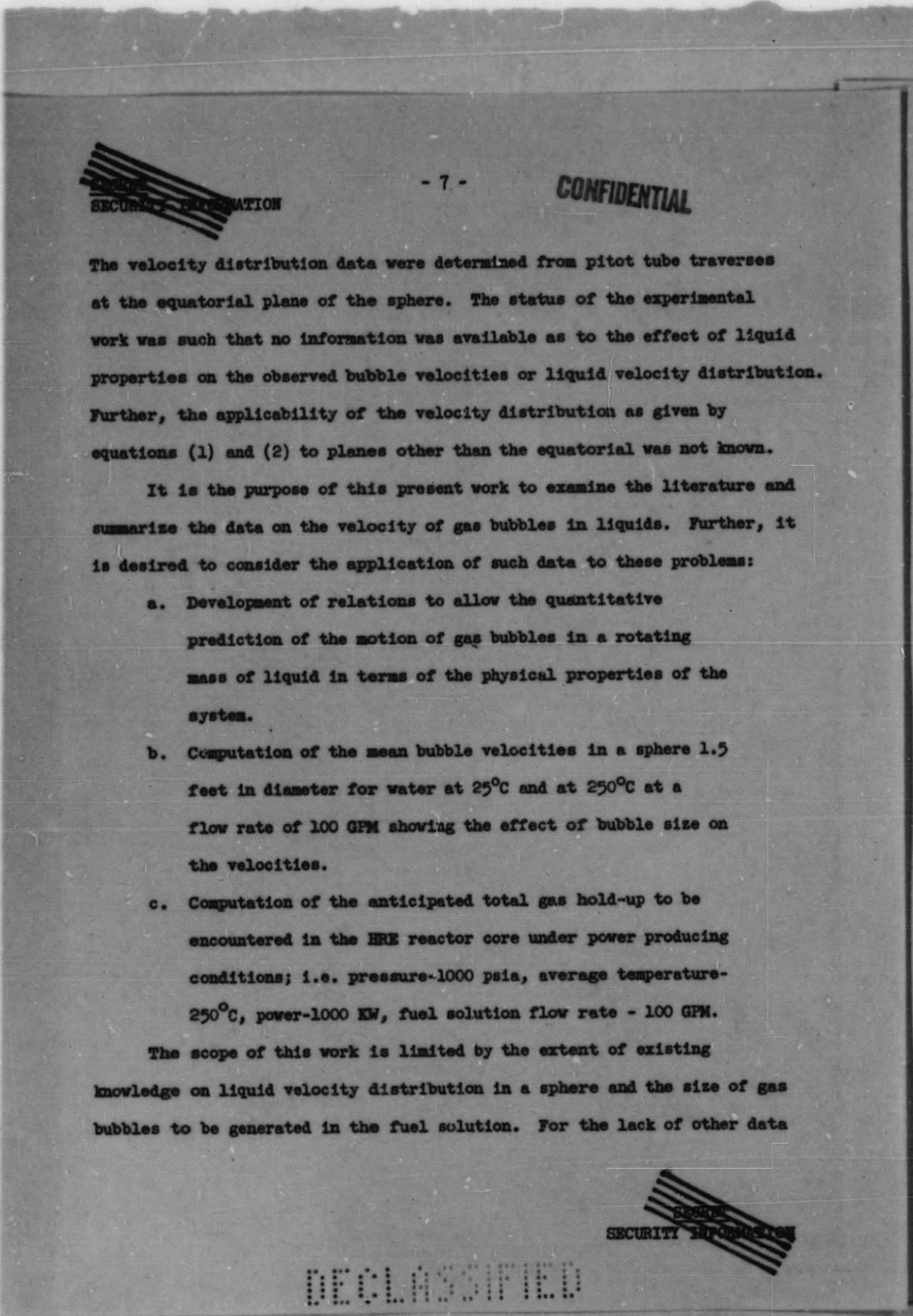


at the present tine, the 11quid velocity distribution data as expressed by equations (1) and (2) $v 111$ be used for all points in the sphere. As surther information on this topic becomes avallable the considerations can b. be revised.

Wilson ${ }^{20}$ presented Information showing that the stze of gas bubbles: to be generated under power producing conditions $1 \mathrm{~s}$ conjectural, and it is possible that gas bubbles $6.6 \times 10^{-5} \mathrm{ft}$ to $2 \times 10^{-2} \mathrm{ft}$ radius may be released from the fuel solution. Again, for lack of specific information at the present time, this range of gas bubbles will be considered in the present work.

\section{DATA OI GAS BUBBLS MOTIOH AID VELOCITIES}

\section{Theory}

The problem of prealeting the velocity of gas bubbles in a 11quid is hydrodynamicel in nature, and falls within the more general problem of the flow of fluids past bodies in a fluid strean, a question which has intrigued Investigators in that Fleld since the time of Nerton. The earlier speculations were based on the hypothesis of an "1deel" fluid having zero viscosity. Reference may be made to texts on classical hydrodynamics such as Lamb?, Milne-Thompson ${ }^{10}$, Green ${ }^{5}$, and Remsey ${ }^{13}$ for the results of such considerations. The conclusions are of little importance since for steady flow the "1deal" fluid offers no resistance to flow past a body imnersed in the fluid stream. This is contrary to experience vith all real fluids.

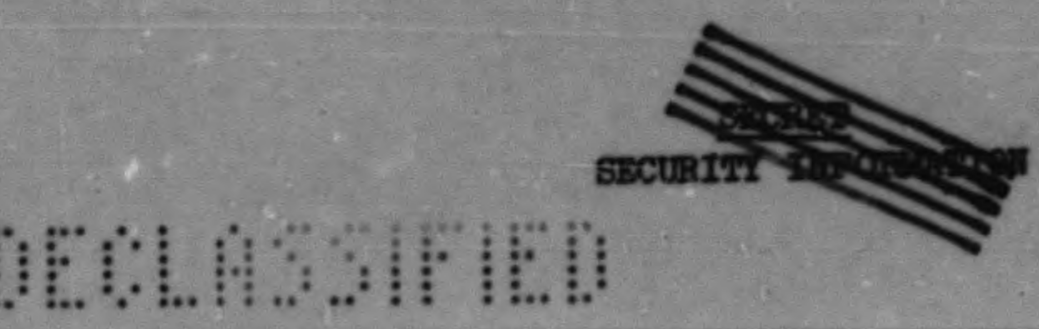




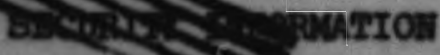

An analysis of the forces involved in the motion of a real fluid loads to the general alferential equations of fluid motion mown as the Navier-Stokes equations.

$$
\begin{aligned}
& \frac{\partial \dot{u}}{\partial t}+u \frac{\partial u}{\partial x}+v \frac{\partial u}{\partial y}+v \frac{\partial u}{\partial z}=x_{1} g c-\frac{g c}{\rho_{1}} \frac{\partial p}{\partial x}+\frac{\mu}{\rho_{1}} \nabla^{2} u \\
& \frac{\partial v}{\partial t}+u \frac{\partial v}{\partial x}+v \frac{\partial v}{\partial y}+v \frac{\partial v}{\partial z}=x_{2} g c-\frac{B c}{\rho_{1}} \frac{\partial p}{\partial y}+\frac{\mu}{\rho_{1}} \nabla^{2} v \\
& \frac{\partial v}{\partial t}+u \frac{\partial v}{\partial x}+v \frac{\partial v}{\partial y}+v \frac{\partial w}{\partial z}=x_{3} g c-\frac{g c}{\rho_{1}} \frac{\partial p}{\partial z}+\frac{\mu}{\rho_{1}} \nabla^{2} v
\end{aligned}
$$

where,

$$
\begin{aligned}
& u, v, v=x, y, z \text { components respectively of the fluid velocity, } f t / s e c \\
& x_{1}, x_{2}, x_{3}=x, y, z \text { components respectively of eny extraneous forces } \\
& \text { acting on a fluid element, pounds force/pound mass } \\
& p=\text { pressure at a point }(x, y, z) \text {, pounds force/(sq } f t) \\
& \text { ge = conversion factor between force and mass } \\
& 32.17 \text { (pounds mass) }(\mathrm{ft}) /(\mathrm{sec})^{2} \text { (pound force) } \\
& \nabla^{2}=\text { Laplacian operator } \\
& \mu \text { - 11quid viscosity, pounds mass/(rt)(sec) } \\
& t=t i m e, \text { sec } \\
& P_{1}=11 q u 1 d \text { density, pounds mass/ cu } \mathrm{ft}
\end{aligned}
$$

Th1s system of equations must be solved aubject to the boundary conditions appropriate to the fluid motion situation involved. Atternpts to obtain solutions by such an appronch are usually haupered by unsurmotntable

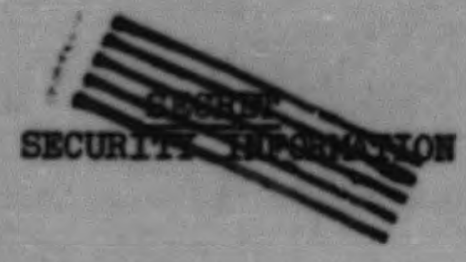


mathematical difficulties, and successful solutions have been achieved for only a feu simple cases. In the main these simple cases have involved only unidirectional flow. However, for the case of symmetrical three dimensional fluid flow around a body immersed in the fluid stream, a solution way be obtained after certain simplifying approximations are made. Stokes ${ }^{16}$ considered the flow of a liquid past a solla sphere at very small velocities. For such small velocities the inertia terms $u \frac{\partial u}{\partial x}, v \frac{\partial u}{\partial y}$, ... become small compared with the frictional terms $\frac{\mu}{\rho_{1}} \nabla^{2} u, \frac{\mu}{\rho_{1}} \delta^{2} v$, ...., and are neglected. W1th these approximations, Stokes solved system (3) for the boundary conditions of zero velocity at the surface of the sphere with the added assumptions of an infinite extent of 11quid and Eravity as the only extraneous force. The important result of the solution 1s that the total liquid resiatance is given by

$$
\mathrm{D}=\frac{3 \pi \mathrm{m} u \mathrm{U}}{\mathrm{gC}}
$$

where,

$D=$ totel 11quid resisting force acting on the spherical sol1d, pounds force

d = diameter of the spherical particle, ft

U = velocity of the spherical particle relative to the 11quid, $\mathrm{ft} / \mathrm{sec}$

This result cen be applied to the rising of a gas bubble in a .11quid under conditions for whlch equation (4) 1s valid. The equation of grav1tationel motion upon application of Newton's second law is

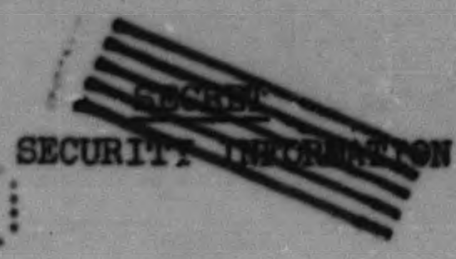


the flow of muids through pipes. Using this analogg, ainensional analysis has been employed to gain some insight coneerning the relation between $C_{D}$ and the veriables influencing 1t. Such treatant gives the result

$$
c_{D}=\Psi(R e)
$$

where

$$
\Psi=\text { arbitrary function, afmensionless }
$$

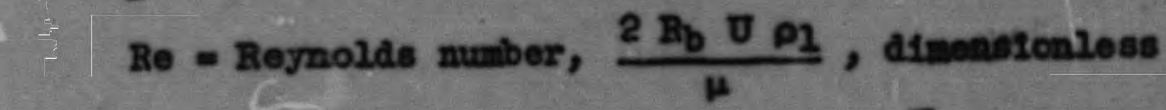

The form of this unknown function, $\Psi$, can be computed for the case where Stokes' law applies by equating the two expressions for the total liquid drag resistance from equations $(4)$ and $(7)$ and essuring a spherical gas bubble. Thus,

$$
\frac{6 \pi R_{b} \mu V}{G c}=\frac{C D \rho_{1} U^{2} \pi B_{b}^{2}}{2 g c}
$$

Solving for $C_{D}$,

$$
C_{D}=\frac{12 \mu}{R_{b} \rho_{1}}=\frac{24}{R e}
$$

For cases where Stokes' lav does not apply the function, $\Psi$, must be determined from experinental data.

A Reviev 으 the Literature

or solid spheres moving in liquids is glven here to serve as a besis for conparing arag coefficients of these with the corresponding values for gas bubbles. Lapple and Shepard ${ }^{8}$ examined the date for solid spheres of 19 invest1gators. These date covered a variety of particle sizes and liquid

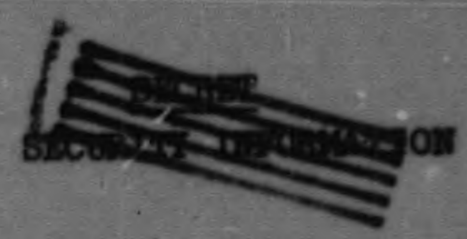




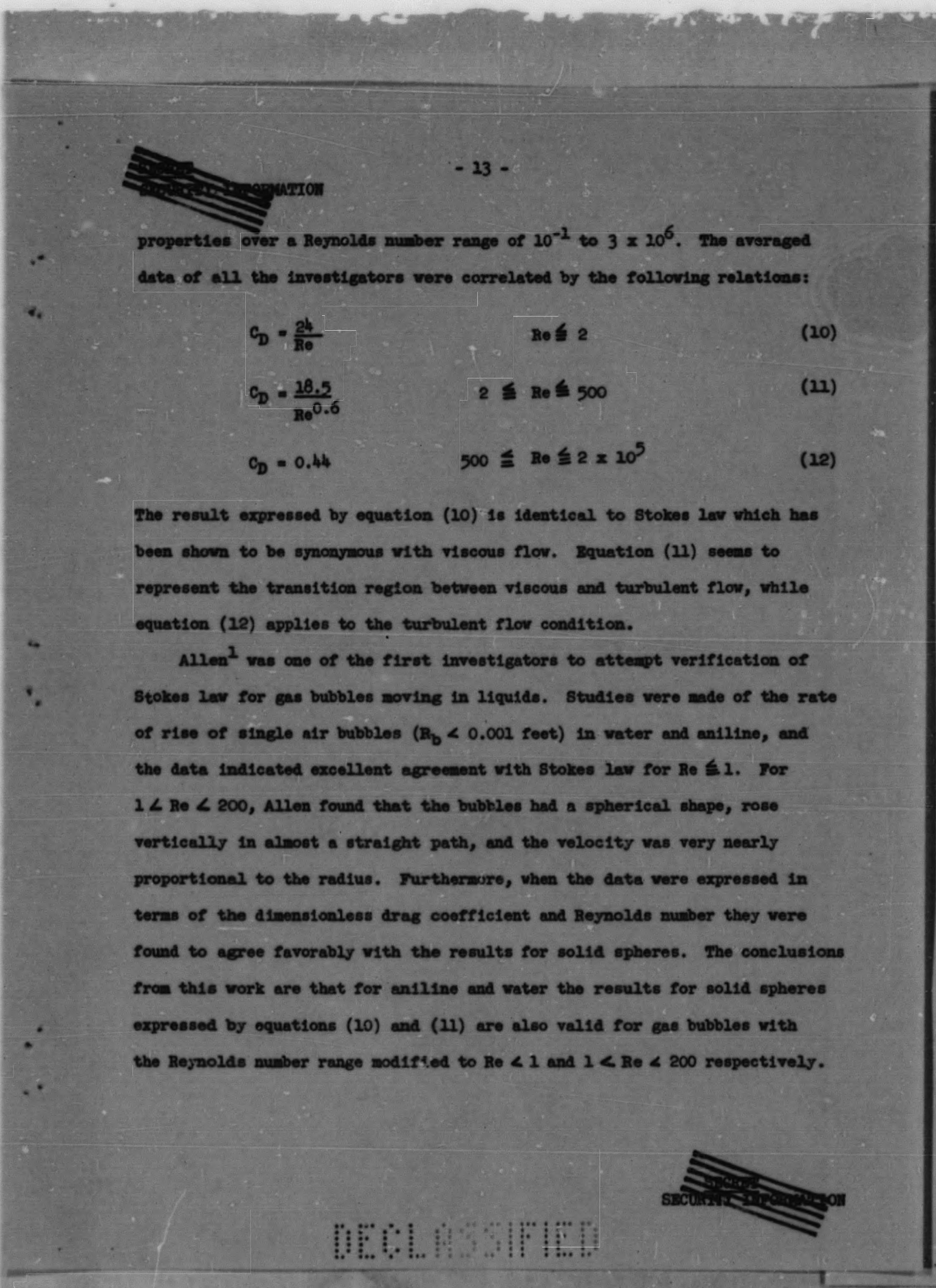


were described which were sindlar to those of Brym. Linited experiments were conducted on the meen velocity of a strean of gas bubbles. No general correlations of these data vere presented.

Robinson ${ }^{14}$ made meesureante of bubble velocities in lubricating o1le for Re 41 . The results confirned those of previous investigators in thet Stokes 1 an 18 applicable to the wovenent of gas bubties in this region.

ralesling ${ }^{6}$ made a dimensional study of the factors affecting the velocity of stean bubbles in verticel boller tubes. It was clatnod that the following dimensionless group functional relationship ahould apply

$$
\frac{v_{\mu}}{\gamma^{c} c}=f\left[\frac{\mu^{4} g}{P_{2} \gamma^{3} g^{3}}, \frac{\rho_{1} B_{b}^{2} g}{\gamma^{g c}}\right]
$$

where

$$
P=\text { arbitrary function. }
$$

Atterpts to determine the functionsl relation were ande vithout success using data given by Schnidt 15 .

Wigner ${ }^{19}$ made some speculations regarding the velocity of gas bubbles In I1quide based on a dimensicnal analjsis of the variables bubble velocity, 11quid density and 11quid viscosity. It vas intended that weh an analysis should give an expression for the terminal velocity of a bubble that was grouring by transfer of material into $1 t$, hence the bubble radius vas not considered in the analysis. Such an ansigsis led to

$$
\frac{U_{\infty} \mu}{\gamma B c}=\rho\left[\frac{P_{1} \gamma^{3} g c^{3}}{\mu^{4} g}\right]
$$

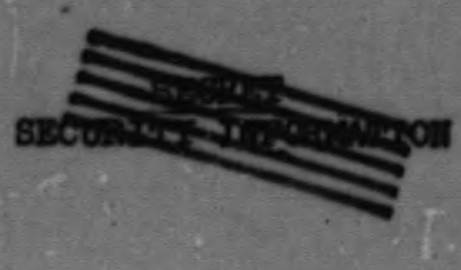




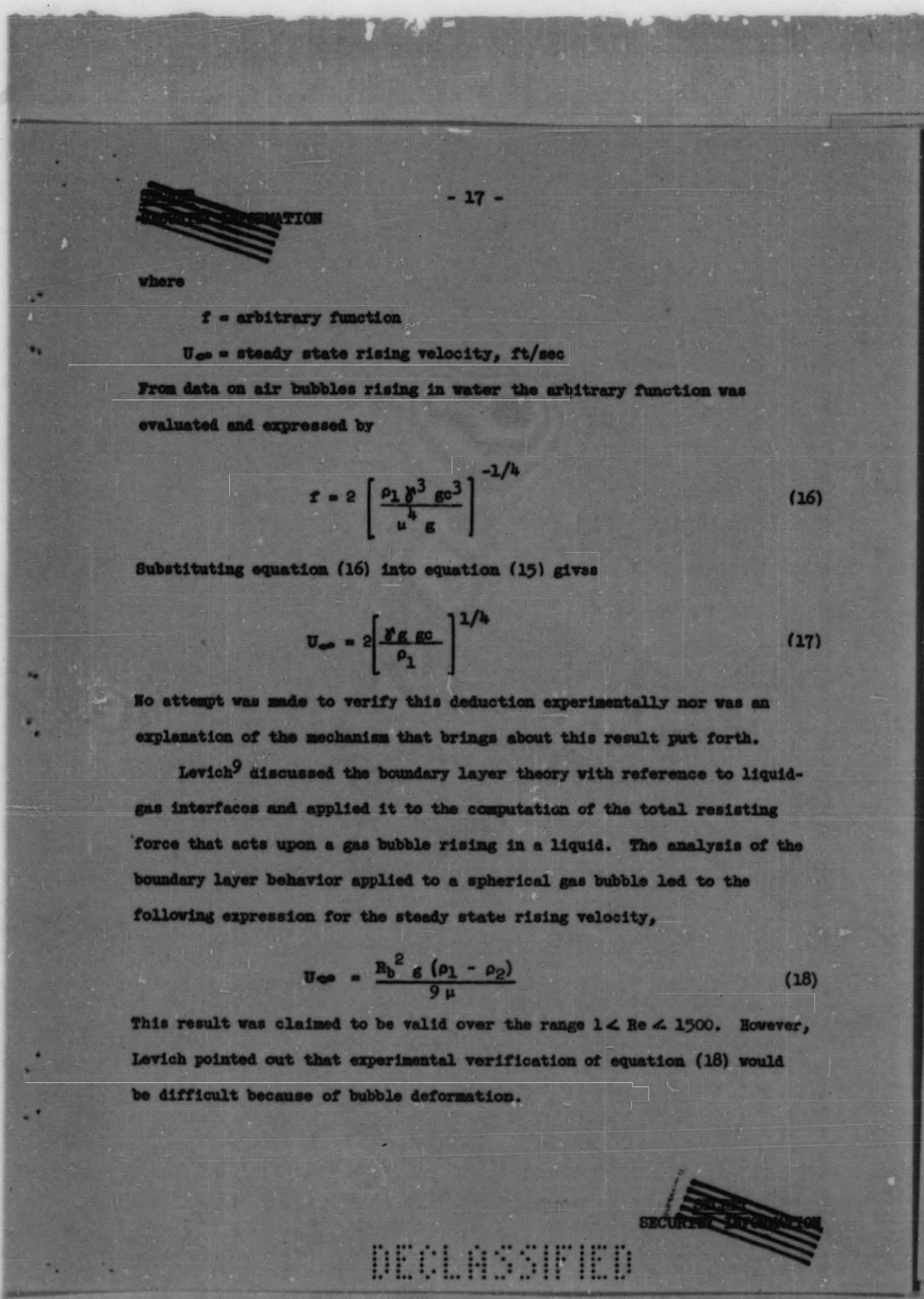




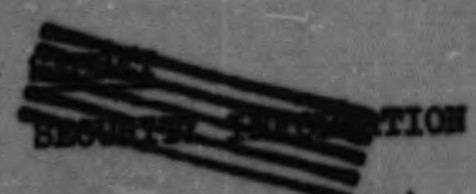

Corodetakeys ${ }^{4}$ conducted experinents on the rate of rise of single eir bubbles in vater and a mumber of nornel alcohols with the exprese purpose of attenpting verification of the conclusions of Levich. In the main the experinental bubble velocities vere approxinately 30 percent lower than those predicted by equation (18), but vere somewhat higher than bubble velocities measured by other investigators under corresponding conditions. Corodetskaye ergued these discrepancles exlat beceuse the bubble velocities are very sensitive to the presence of the slightest trace of impurities in the 11quids used, that all the 11quids he used in the work were carefully purified wereas previous investigators had Ignored this precesution. Data vere presented to show that concentrations of surface-active substences as Low as $10^{-6}$ molar are eufficient to affect the velocity of bubbles in 11quids, these effects being attributed to changes in "Interfacial viecosity." Datte, Ilapler and Ioritt ${ }^{3}$ made measurements of the velocity of single air bubbles in vater. Their anta egree vith those of Allen and Myagi under corresponding conditions. In the range of gas bubble elees described by Brym as "large bubbles" ( $\mathrm{B}_{\mathrm{b}}>0.013$ reet), the veloc1ties as aeasured by these Invest1gators vas almost independent of size.

Verschoor ${ }^{18}$ studied the motion of a stream of air bubbles in a colum of 11quid. Measurements of neen bubble velocity vere made for alfferent rates of air passing through the colum vithout neasuring the bubble size. Attenpte vere ande to correlate the date using the dimensionless groups suggested by raissling. Wo general relationships vere presented.

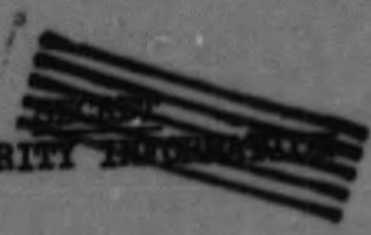




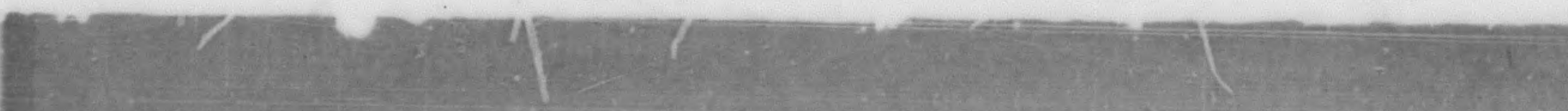

Van Trevelen and Hoft1jzer ${ }^{17}$ made measurements of the velocity of a strean of alr bubbles rising in vater, cyclohexane, mineral o1l and aqueous solutions of elveerine and saponine. When the resulte vere expressed in terms of the drag coefficient and Reynolds nusber, deviations fron the correlations for solid ppheres were obtained similar to the revults of o'Brien and Coslino. Ilo general relationships in terms of the physical properties of the systen vere given.

Studies at the Univereity of Tennessee

As a phase or a long range project at the University of Tennessee Involving nass transfer in 11quid-gas bubble systems, the motion of alr bubbles in 22 different 11quids vas studied. The express purpose of the vork was to dlecover general correlations of the velocity and the Arag coefficients of gas bubbles in terms of the bubble size and physical properties of the system.

The experinentel vork consisted of determining the steedy state velocity of single bubbles of lmown size rising in liquide of predetermined physical properties. The range of bubble sizes and physical properties used In the studies were such that a Reynolds muber renge of 0.5 to 2500 was covered.

Typlcal results of the steady state velocity of afr bubbles rieing In water and a ethyl acetate-cottonseed ofl solution as a functicn of the bubble radius are given in $\mathrm{r} 1 \mathrm{gure}$ 1. Date for some of the other systems studied are show in Figure 2 as a plot of the drag coefficient versus the Reynolds number. The data as given agree favorably vith those of previous

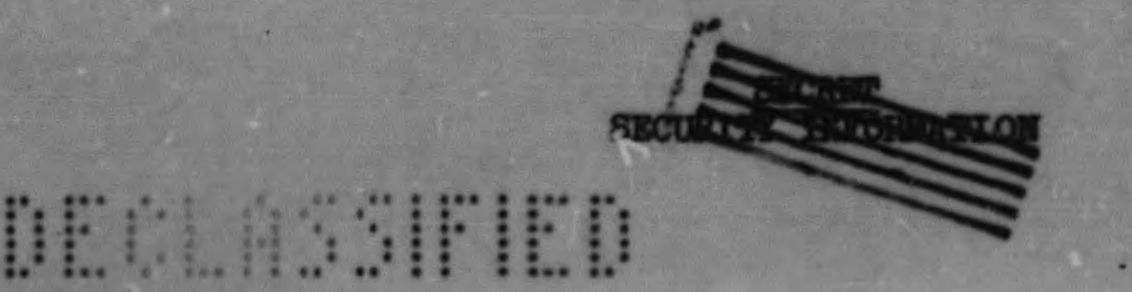




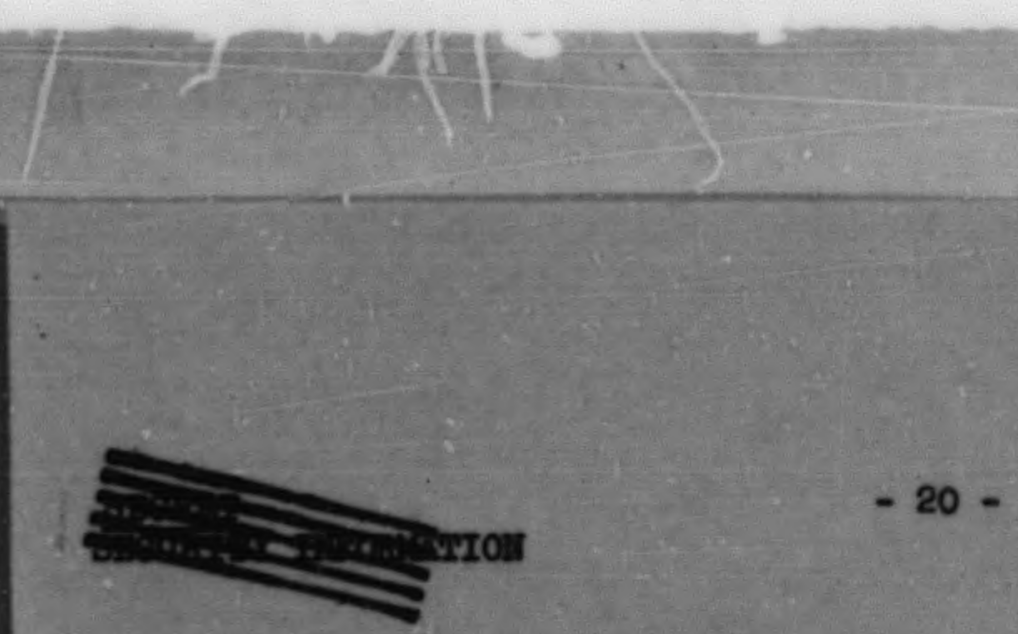

Investigators. As observed by 0'Brien and Gosilne the plot of the Arag coefficlent versus the Reynolds number is not a general correlation for the behavior of gas bubbles and other parameters are involved.

As may be noted in Figures 1 and 2, four distinct regions of behavior are exhibited by the motion or gas bubbles in a given 11quid. The riret two regions correspond to the motion of solid spheres in 11quids. The third and fourth regions Indicate the departure from eimilarity to the motion of sol1d spheres. Without discussing the empiricel and theoretical methode used in the analysis of the experimental data, the drag data fron all the experiments could be expressed by the relations given in Table I.

\section{TABLB I}

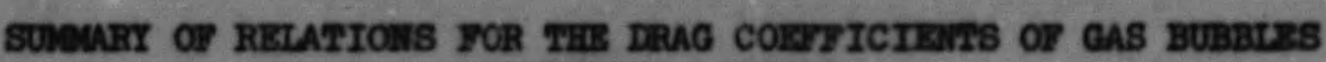
Movrmo in LIQUIDs

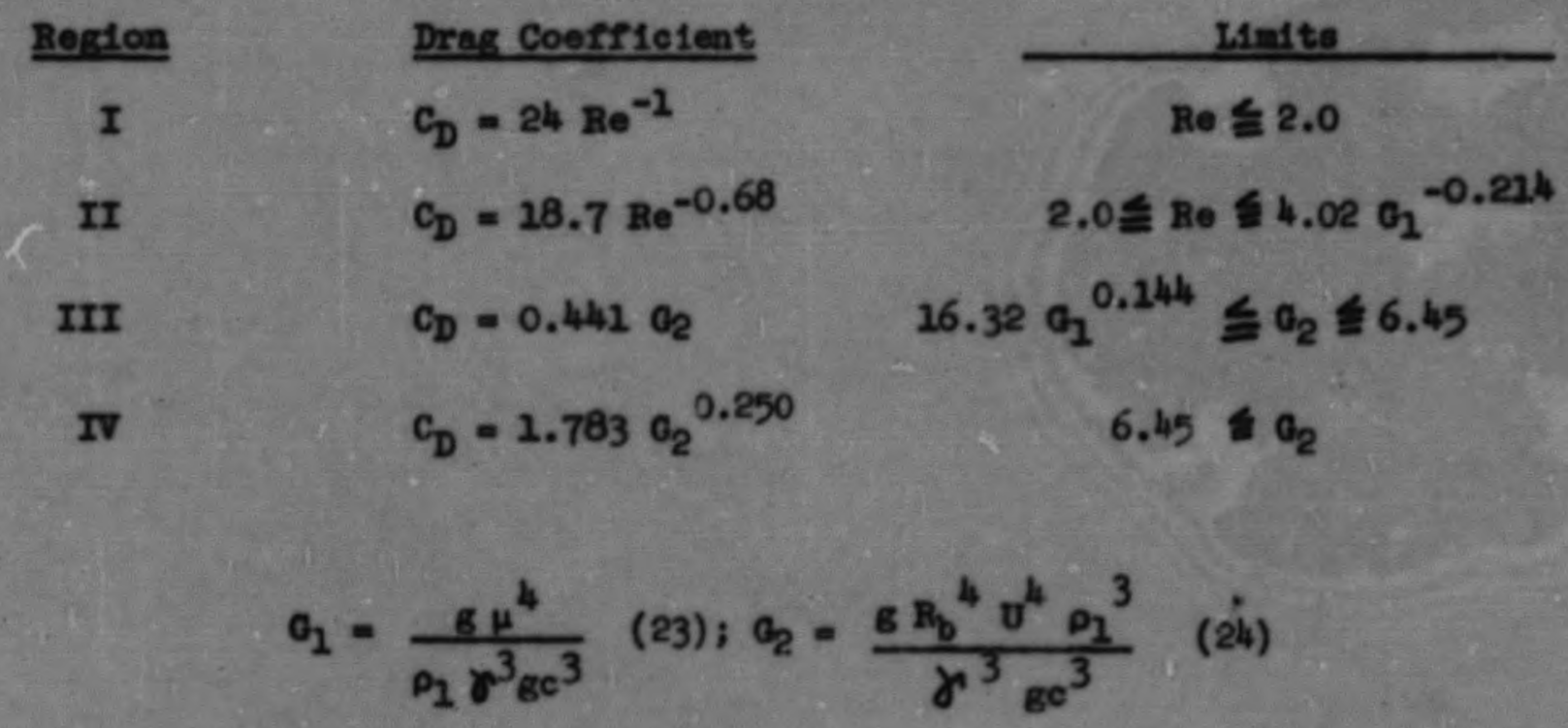




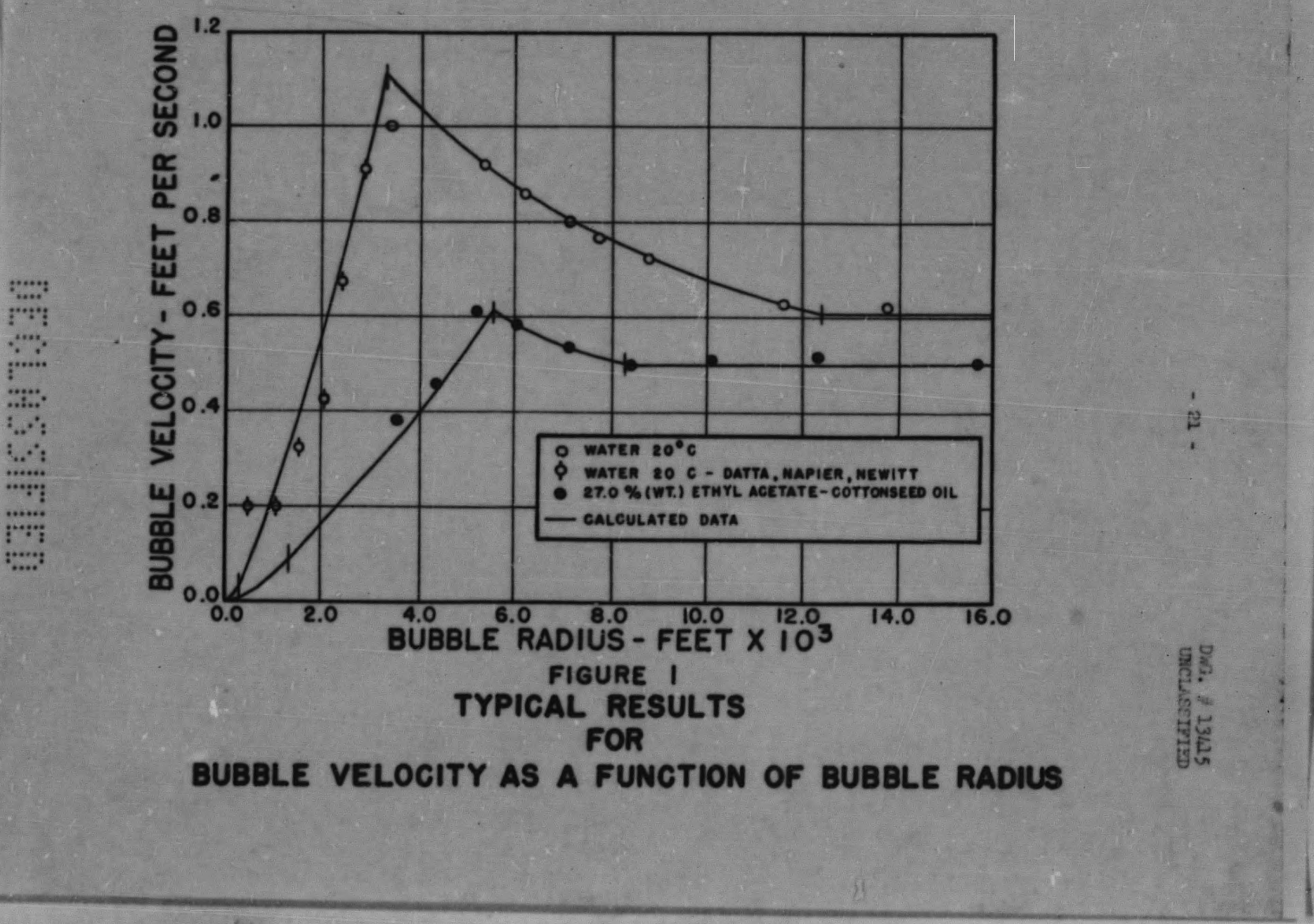




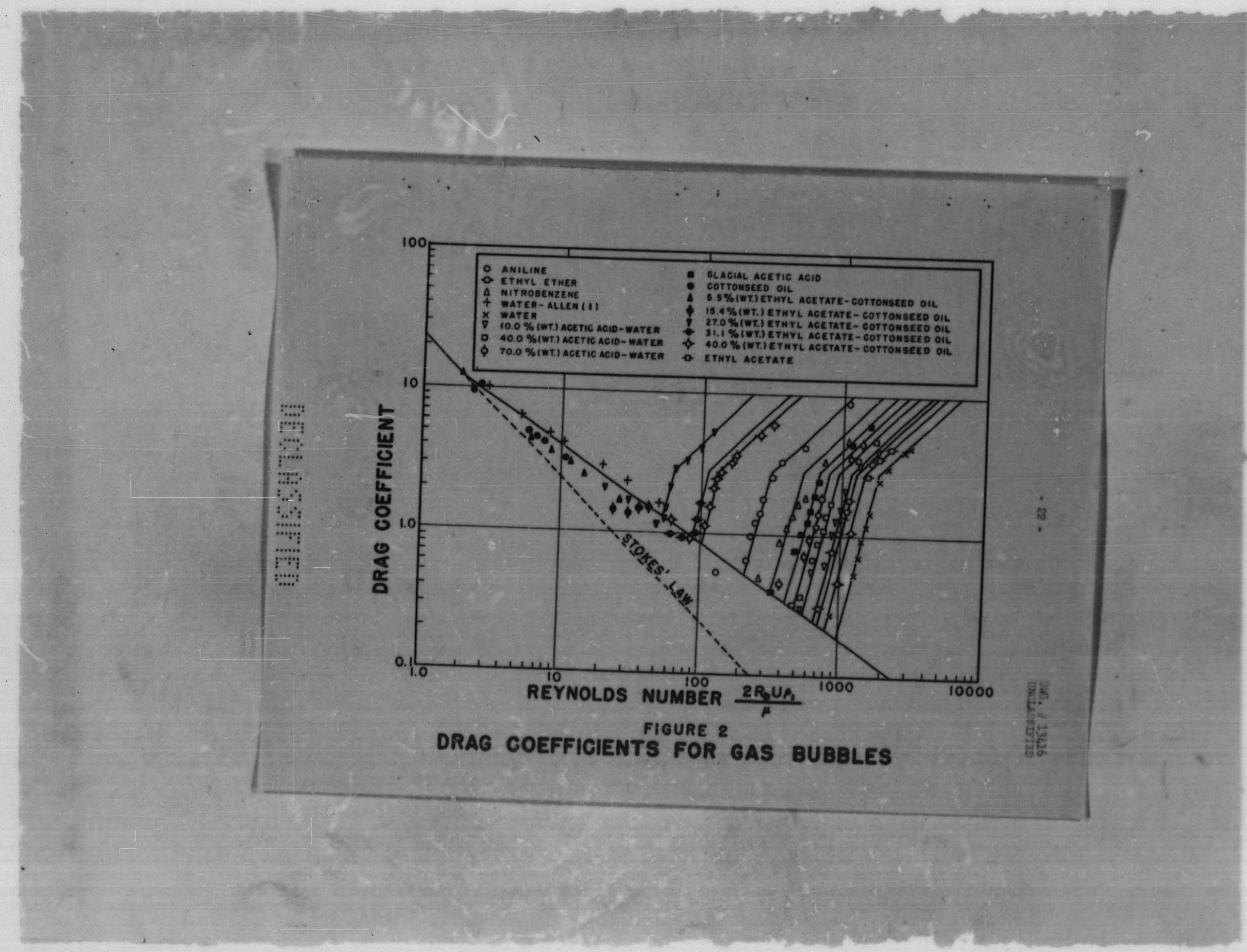




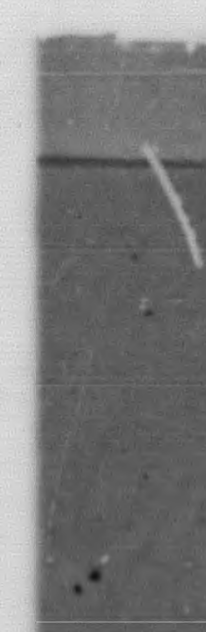

$-23-$

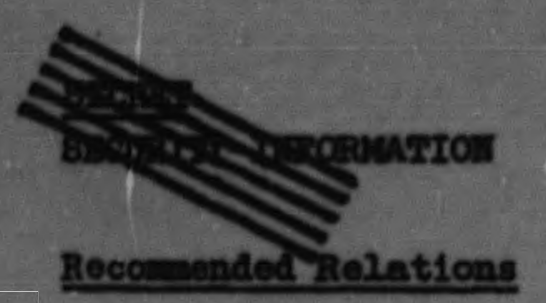

It 1 proposed to use the correlations expressed in Fable I for the arag characterietice of gas bubbles moving in 11quids in this present work. Th1s proposal is besed primarily on these factors:

A. Wo other general correlations for the drag coefficients of gas bubbles moving in 11quids are knom.

b. Bven though the correlations are based on data from the motion of eingle gas bubbles, the corresponding data for nasses of gas bubbles probably are not seriously afferent.

c. Intimate relation of the author with the vork at the Univeraity of Tennessee.

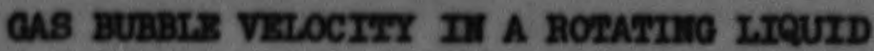

\section{Developgent of Basic Bquations}

The accelerating motion of a gas bubble in the rotating ilquid of the BRE core is approxinated elosely by a oingle equation for the radial component of the totel notion, thus

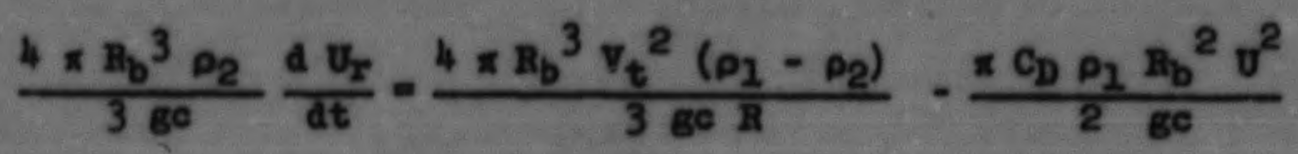

where,

$$
\begin{aligned}
& \text { R = position radius neasured from the vertical axis } \\
& \text { of the sphere, ft } \\
& t=t i m \text {, sec }
\end{aligned}
$$

$\rho_{2}=$ gas density, pounds wass/ou $\mathrm{ft}$

$\mathrm{U}_{\mathrm{x}}=$ radial velocity of the bubble relative to a fixed coordinate system, $\mathrm{ft} / \mathrm{sec}$ 


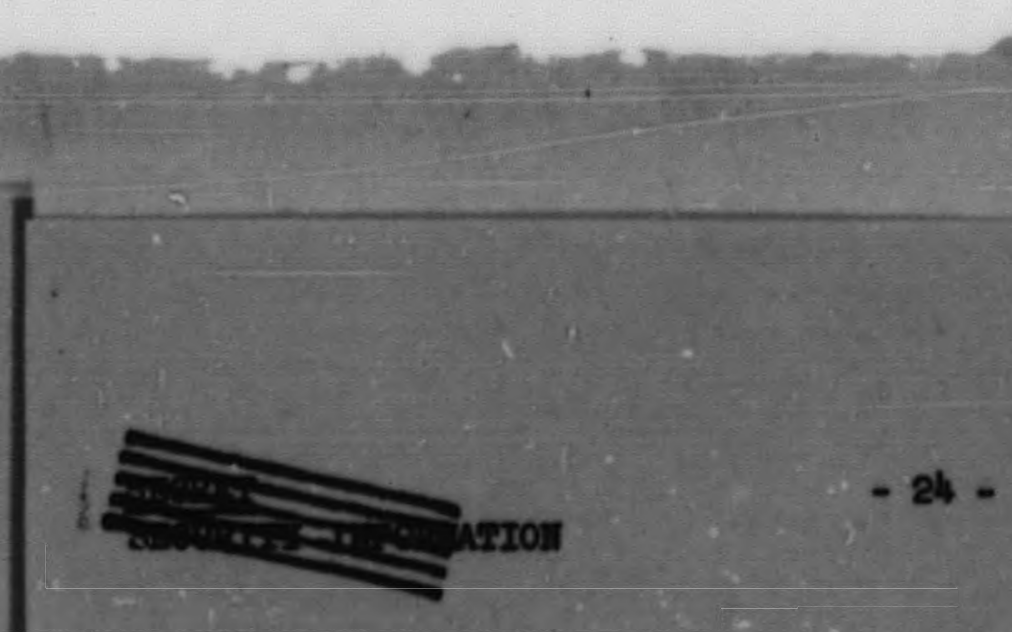

Such an expression is based on neglietble sotion of the gas bubble vith respect to the 11quid in the tangent1al and verticel. Afrections. Ifence,

$$
v_{r}=v_{r}+v
$$

The combination of equation (26) and the relations for the drag coerrielent as given by equations (18) through (24) would theoreticality pernit an analytical solution to equation (25). Such a procedure is extrenely inpractical and numoricel integration is indicated. Hlovover, upon attenpting such numerical integration, it is found that for a fixed value of bubble position radius, $\mathrm{R}$, the acceleration to a terminel velocity 10 elmost Instantaneous. As a result, 11ttle accuracy is sacrificed by assuning

$$
\left.\frac{d v_{x}}{d t}\right|_{R=\text { constant }} \equiv 0
$$

Incorporating this approximation into equation (25) leads to the simplification

$$
c_{D} v^{2}=\frac{8 \mathrm{~A}_{\mathrm{b}} \nabla_{t}^{2}\left(p_{1}-n_{2}\right)}{3 \mathrm{R} p_{1}}
$$

Substituting the relations for the drag coefficient as given by equation (19) through (24) gives these expressions for the radial velocity,

$$
\begin{aligned}
& v=\frac{\nabla_{0} \rho_{1} R_{b}^{2}}{12 \mu}, \quad v \leqq \frac{\mu}{\rho_{1} R_{b}} \\
& \mathrm{U}=0.155 \mathrm{z}_{\mathrm{G}}^{0.758}\left[\frac{\rho_{1}}{\mu}\right]^{0.515} \mathrm{~B}_{\mathrm{b}}^{1.272} \\
& \frac{\mu}{D_{1} \mathrm{~B}_{\mathrm{b}}} \leqslant v \notin \frac{2.02 \mu}{D_{1} \mathrm{I}_{\mathrm{b}}} \mathrm{O}^{-0.214} \\
& \text { : }
\end{aligned}
$$

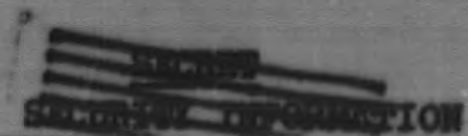




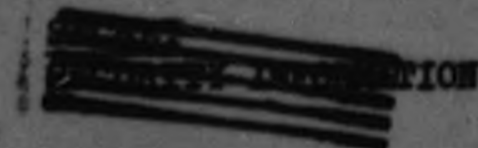

$\delta=1.146\left[\frac{z_{G}}{\mathrm{~g}}\right]^{0.167}\left[\frac{\gamma_{\mathrm{gC}}}{\mathrm{R}_{\mathrm{P}}}\right]^{0.500}$,

$$
\frac{2.01}{g^{0.250}} a_{1}^{0.036}\left[\frac{\gamma_{B C}}{\rho_{1}}\right]^{0.750} \frac{1}{\mathrm{R}_{\mathrm{b}}} \leqq v \leqslant \frac{1.594}{0.250}\left[\frac{\gamma_{\mathrm{Bg}}}{\rho_{1}}\right]^{0.750} \frac{2}{\mathrm{R}_{\mathrm{b}}}
$$

$$
\begin{aligned}
& v=0.825\left[\frac{\mathrm{u}_{\mathrm{G}}}{\mathrm{s}}\right]^{0.083}\left[\frac{\gamma_{\mathrm{gc}}}{P_{1}}\right] \\
& \frac{1.505}{\mathrm{~g}^{0.250}}\left[\frac{\gamma_{\mathrm{BC}}}{P_{1}}\right]^{0.750} \frac{1}{\mathrm{~B}_{\mathrm{b}}} \leqslant v
\end{aligned}
$$

where $\quad z_{G}=\frac{8 v_{t}^{2}\left(p_{1}-p_{2}\right)}{3 R \rho_{1}}$

Th1s system of equations permits the computation of the gas bubble velocity at a specified point in the rotating liquid in terme of the bubble size, physical properties of the syoten and the velocity of the 11quid. Conputation of Maxtmin Gas Bubble Residence T1en

Some of the experimontal work on gas hold-up in the Birs core described In ORIL-630 involved the injection of moasured volumes of gas bubbles into the mock-up spheres at the 11quid inlet. From both motion pleture studies and gas hold-up measuremonts, it was found that $0.25-0.40$ seconds vere required for gas bubbles to move from the 11quid inlet to the central gas vold (1.e. $\mathrm{B} \cong 0.65 \mathrm{ft}$ to $\mathrm{R} \cong 0.01 \mathrm{ft}$ ). The s1zes of bubbles involved in these studies were not known prec1sely but it was estimated that the sizes were from $0.10-0.30$ inch in dianeter.

In order to show the applicability of the previous equations for the gas bubble velocity in a roteting liquid, the maximum gas bubble residence time (the time required for a bubble to wove froil the 11quid inlet to the 


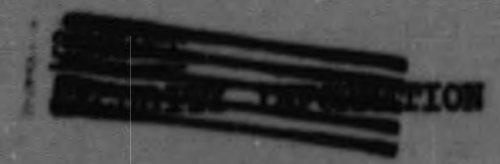

$-27=$

c. Compute the absolute radial velocity of the gas bubble, $\nabla_{r}$, by equation (26) ueing the result of cosputation (b) and the value of $\nabla_{x}$ froen cosputation (a)

a. Repeat the above computations for a number of values of the position radius in the range $0.02 \leqslant \mathrm{R} \leqslant 0.65 \mathrm{ft}$.

- Colipute the maximan gas bubble residence $t 1 m, t, t$ by ovaluating the integral,

$$
t=\int_{0.65}^{0.02} \frac{d \mathrm{R}}{\frac{\mathrm{U}_{\mathrm{r}}}{\mathrm{T}}}
$$

this may be done graphically by a plot of this type

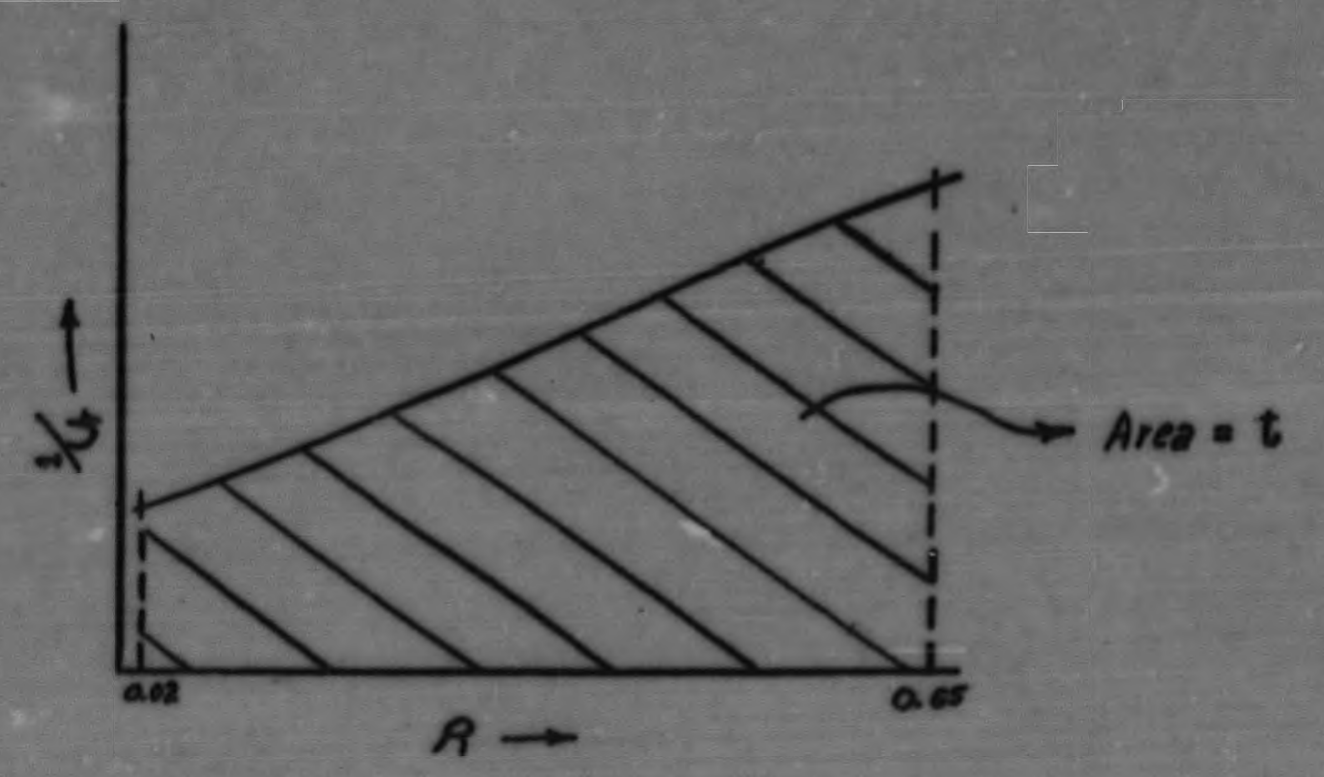

As an alternate procedure this integral an be evaluated numericaliy.

The results of computations using this procedure are shom in Figure 3 and Figure 4 giving the maxtmum gas bubble residence time as a runction of the gas bubble eize. Jigure 5 gives the radel bubble velocity for a bubble 


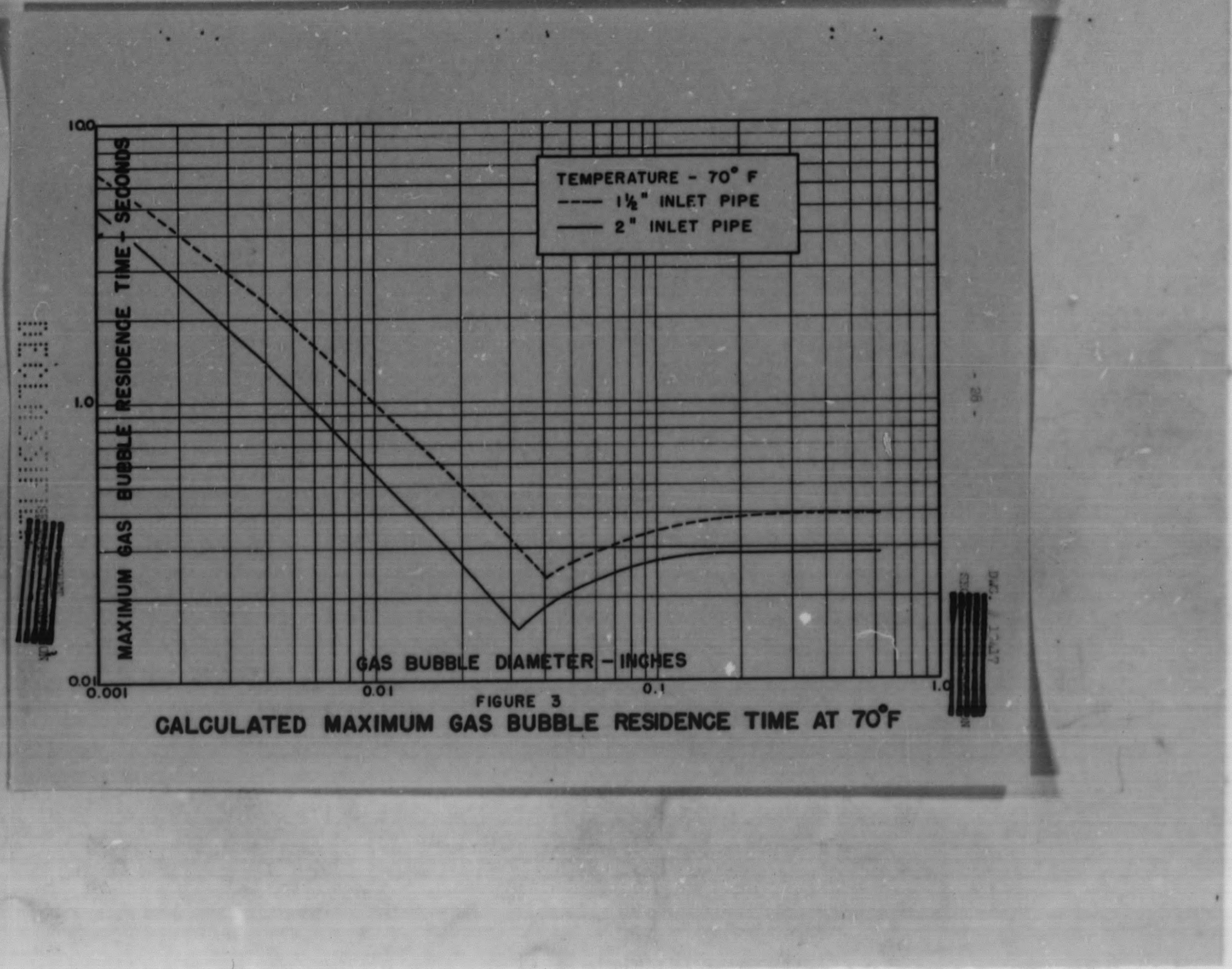




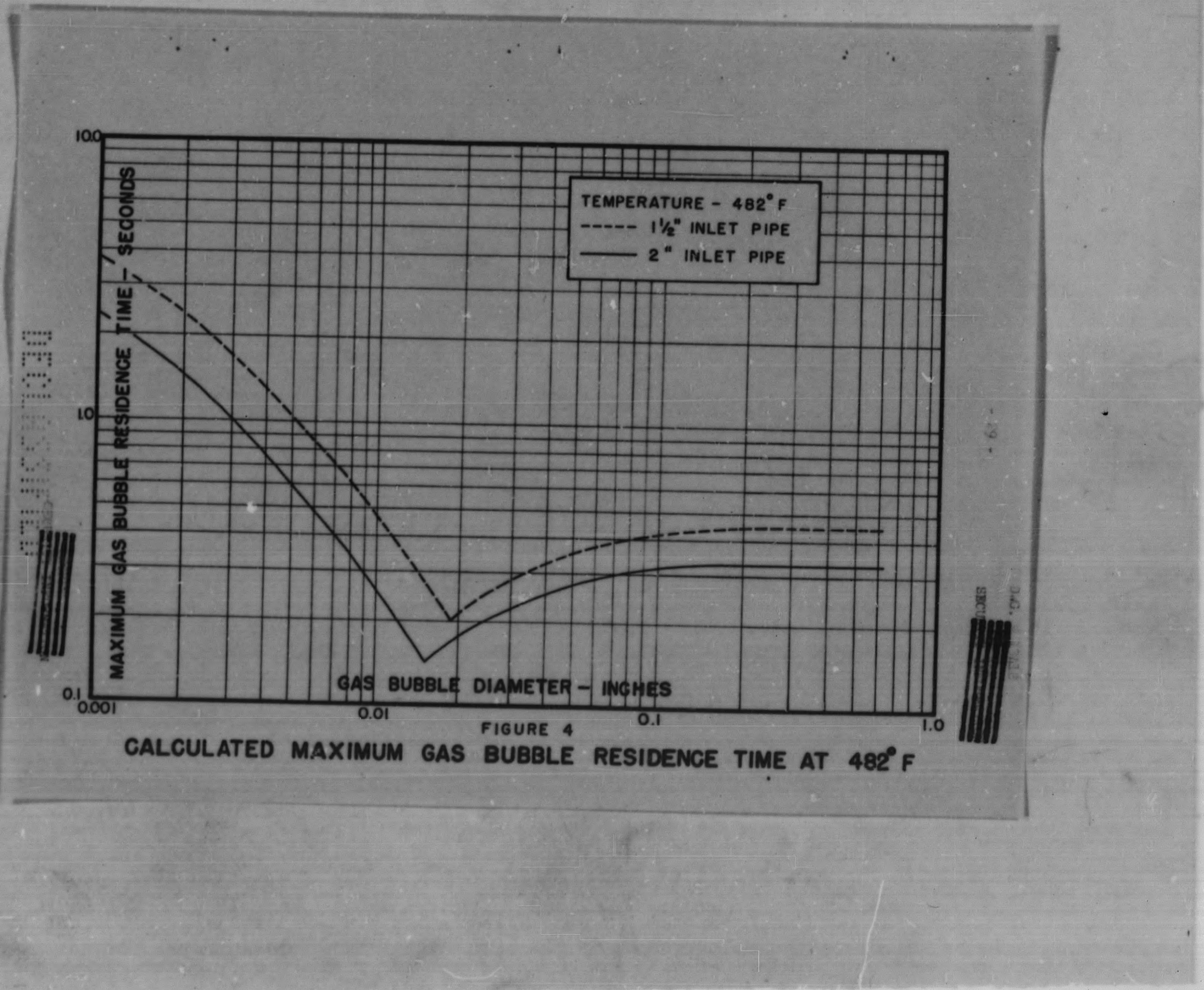




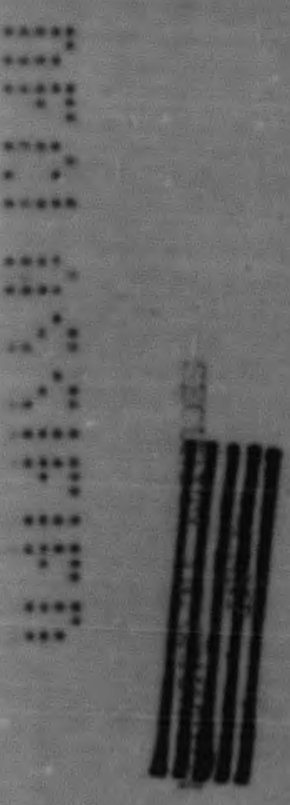

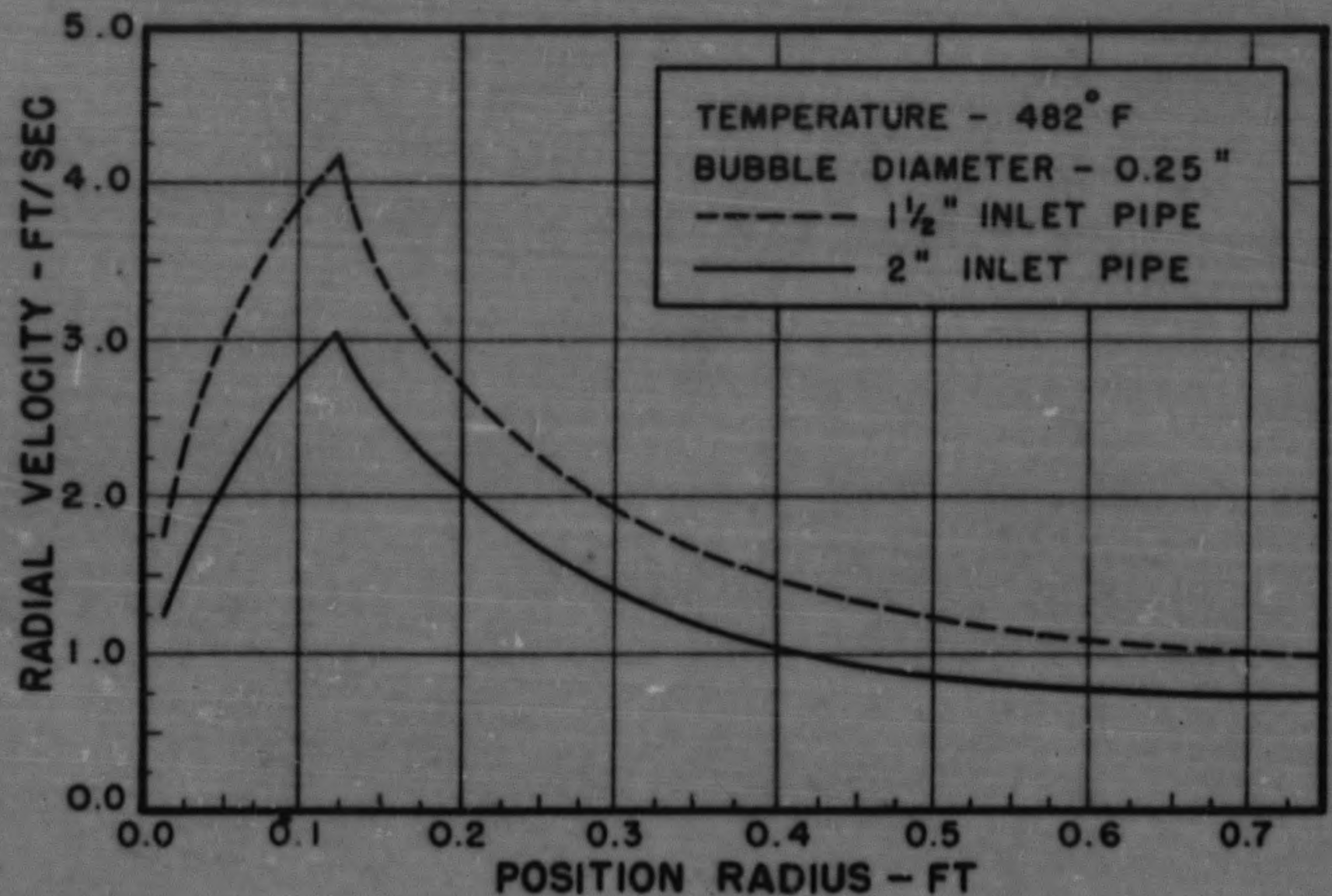

FIGURE 5

CALCULATED GAS BUBBLE RADIAL VELOCITIES IN THE HRE CORE 



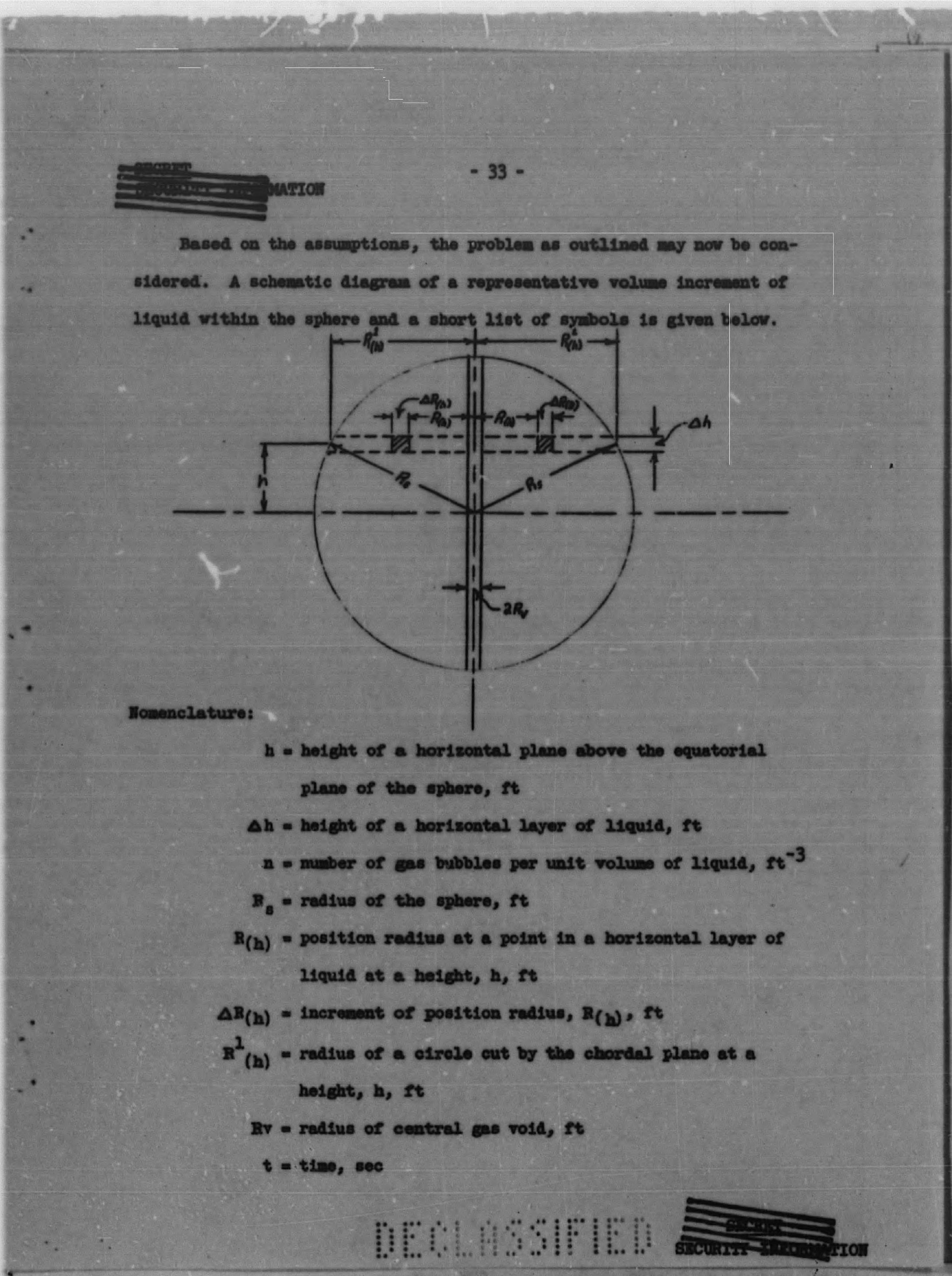


W, ${ }^{\mathrm{U}}(\mathrm{h})=$ mean radial velocity of all gas bubbles moving In a laysr of 11quid at a helght, $\mathrm{h}, \mathrm{ft} / \mathrm{sec}$ $v_{b}=$ volume of a gas bubble, cu ft

$v_{G}=$ volume of ges generated per unit time per unit volume of 11quid, $\sec ^{-1}$

Fow considering the annular element of liquid volume as formed by the increment of position radius, $\Delta \mathrm{R}_{(\mathrm{h})}$, at a point ${ }^{\mathrm{f}}(\mathrm{h})$ with a helght, $\Delta \mathrm{h}$, It ma be show that the rate of change of the number of bubbles is given by

$$
\frac{\partial n}{\partial t}=-v_{(h)} \frac{\partial n}{\partial R}-\frac{v_{(h)} n}{R}+\frac{v_{G}}{v_{b}}
$$

Since for steady state conditions, $\frac{\partial n}{\delta t}=0$, then $n$ becomes a function of ${ }^{R}(h)$ only and equation (31) 18 reduced to the ordinary differential equation

$$
\frac{d n}{d R(h)}+\frac{n}{R_{(h)}}=\frac{v_{G}}{\bar{v}_{(h)} v_{b}}
$$

this squation is integrated to

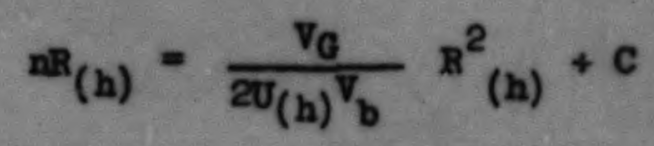

where $\mathrm{C}$ is a constant of integration. This constant may be evaluated from the boundary condition

$$
\mathrm{n} \rightarrow 0, \mathrm{R}_{(\mathrm{h})} \rightarrow \mathrm{R}^{2}(\mathrm{~h})
$$


Substituting this condition in equation (33), the gas bubble concentration alstribution for steady state conditions is given by

$$
n=\frac{v_{G}}{{ }^{20}(h)^{v_{b}}}\left[{ }^{R}(h)-\frac{B^{2}(h)^{2}}{{ }^{R}(h)}\right]
$$

Equation (35) Elves the gas bubble concentration as a runction of B(h) within the horizontal layer of helght, $\Delta \mathrm{h}$, and then the number of gas bubbles in the annular elenent of 11quid volume becomes

$$
\Delta \mathrm{H}=2 \mathrm{R} \Delta \mathrm{h} \mathbf{R}(\mathrm{h})^{\mathrm{n}} \Delta \mathrm{R}(\mathrm{h})
$$

where $\Delta \mathrm{I}$ represents the number of gas bubbles contained in this volume element. Now assuming the use of the celculus and pessing to the linit as $\Delta \mathrm{R}_{(\mathrm{h})} \rightarrow 0$ and $\Delta \mathrm{h} \rightarrow 0$

$$
a n=2 \pi n^{R}(h) d R(h) a h
$$

How Integrating over the entire liquid volume, the total mumer of gas bubbles contained in the sphere becomes

$$
\Sigma=4 \pi \int_{0}^{R_{8}} \int_{B v}^{R^{2}(h)} n R_{(h)} d R(h) d h
$$

where $\Sigma$ II represents this total number of gas bubbles. Letting $\nabla_{B}$ represent the volume of gas bubbles contained in the sphere and substituting the value of a from equation (35)

$$
v_{H}=2 \pi v_{\theta} \int_{0}^{R_{\theta}} \int_{R v}^{R^{l}(h)} \frac{1}{v_{(h)}}\left[R_{(h)}^{2}-R_{(h)}^{2}{ }^{2}\right] d(h) d h
$$



The total gas hold-up in the sphere nay be computed by

$$
\$ \text { Bold-Up }=\frac{3\left[V_{B}+2 \pi B_{v}^{2} B_{B}\right]}{4 \pi R_{\theta}^{3}} \times 100
$$

Using these results, the per centage total gas hold-up has been computed for the $\mathrm{BR}$ reactor core under power producing conditions for a range of bubble gizes. These results are shown graphlcelly in Figure 6. No experimental data are available for comparison. These computations are based on a value of $\mathrm{Bv}=0.02 \mathrm{ft}$ (approximately 0.5 inch diemeter gas vold).

\section{DIscussiom of TrE REsurs}

A number of assumptions and approxf eations to the actual Hig conditions have been ande in this work. It is desirable to evaluate the effects of such epproximations and to Indicate the type of data that are needed to elininate the approximations.

The basic epprcxination with regard to the motion of gas bubbles in the IRS reactor core is in the description of the liquid velocity given by equations (1) and (2). As has been pointed out these relations result from Iinited exporimentel data, and are knom to be contradictory to quelitative Infornation obtained in flow pattern studies now in progress at Oak Ridge Ilational Iaboratory. As quantitative information is made available from these studies and fron similar etudies now in progress at other laboratories, the computations can be revised to account for the more complete information on the liquid flow within the spherical core. It is felt that these revisions will be such that the verticel motion of the gas bubbles is secounted for 
In the form of another equation of gas bubble motion in this direction similar to equation (25). A revision of this type will add greatly to the computational requirements but will permit a definitely more accurate description of the gas bubble motion within the reactor core.

It was necessary to use Arag coefficient and velocity data for single gas bubbles in this present work since quantitative information on the motion of a stream of gas bubbles is not known. However, the limited data that are avallable Indicate that this is accurate to approximately 25 percent. A project on the determination of such deta on gas bubble streams is in progress at the University of Tennessee, Department of Chemical kngineering. Some results from this project should be avallable by August, 1952 and revisions to this work can be made in 11ght of the new data.

It is to be noted that the procedure of assuming a size of gas bubble has 101 to positive results regarding the bubble motion and gas hold-up in the reactor core. Since little is know regarding the size of gas bubbles to be encountered in the reactor core, it was necessary to make computations for a range of bubble sizes thet Included all the probable sizes. Such a range of gas bubble sizes was taken to be $0.001^{\prime \prime}$ to $0.6^{\prime \prime}$ equivalent spherical dianeter.

The other approximations and assumptions were for the most part computational In nature, 1.e. "short cuts" to expedite the nuwerical vork. In all such cases these approximations did not affect the results by more than 5 percent. 
1. Allen, H. S, Ph11. Mag., , 50, 323 (1900)

2. Bryn, T., Porsch. Geblete Ingenfeurx. 4, No. 1, 27(1933)

3. Datta, R. L., Xispier, D. H., and Invitt, D. M., Trans. Inst. Chem. Bngrs., (Iondon), 28, 3(1950)

4. Gorodetskaya, A., J. Phys. Chem. (USSR), 23, 71(1949)

5. Green, S. L., Hydro-and Aero-dymamles, S1r Isaac P1tman and Co., Ltd., London (1938)

6. Kalssling, F., Forsch. Geblete Ingenteurw., 14, 30(1943)

7. Lamb, H., Hydrodynam1 cs, Dover Publications Co., New York, IeW York., 6 th Eaition (1945)

8. Lapple, C. B. and Shepherd, C. B., Ind. Ing. Chem., 32, 605 (1940)

9. Levich, v, G., J. Expt. Theoret. Fhys. (USSR), 19, 18(1949)

10. Milne-Thompson, L. M., Theoret1cal Bydrodymamies, Macmillan and Co., Ltd., London (1938)

11. M1yag1, 0., Ph11. Mag., 52, 112(1925) Abetract of Tech. Repts. Toholu Imp. Univ., 4, 茫. 2 (1924)

12. O'Brien, M. P. and Gosilne, J. E., Ind. Eng. Chem., 27, 1436(1935)

13. Ramsey, A. S., A Treat1se on Hydrodynamics, Pt. II., G. Bell and Sons, Ltd., London (1947)

14. Rob1nson, J. V., J. Phy. Coll. Chem., 51, 431 (1947)

15. Schmidt, B., Yorschungsheft, 365 (Be1laze zu Forsch. Geblete Ingenieurv. $)(1934)$

16. Stoikes, G. G., Wathematical and Physical Pepers, Vol. I, Cambridge Un1versity Press, London (1880)

17. Van Krevelen, D. W. and Hoft1jzer, P. J., Chem. Ing. Progress, 46, 29(1950)

18. Verschoor, H., Trans, Inst. Chem. Engrs. (Iondon), 28, 42(1950)

19. W1gier, B. P., The Rate of R1se of Air Bubbles, ABCD-1983(1948)

20. Wilson, R. H., Llterature Survey, Be: Bubble Forration,

$50-4-148$

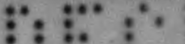

sids 



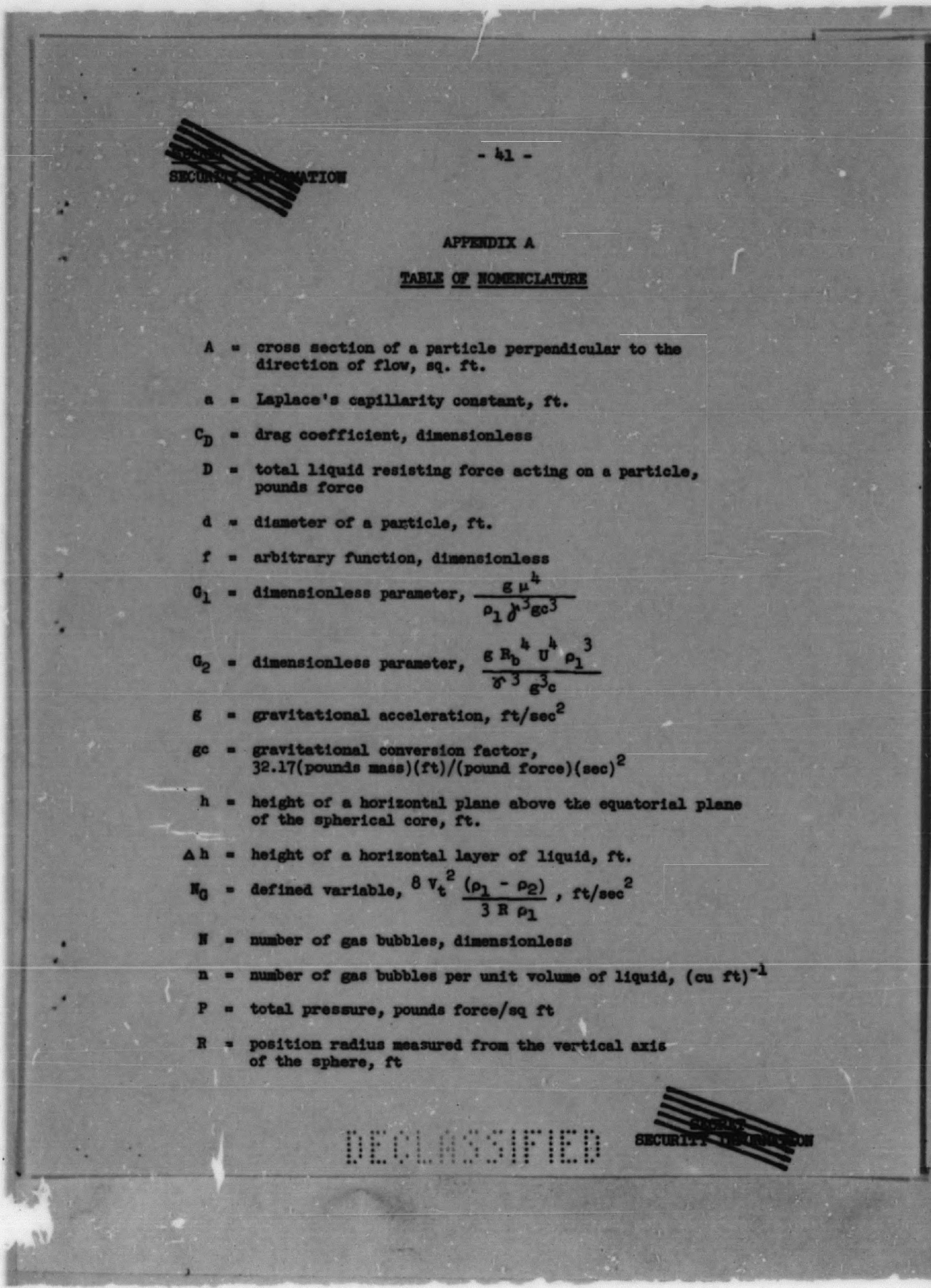


$B_{b}$ - equivalent opherical radius of a ga bubble, ft

$\mathrm{B}_{\mathrm{S}}=$ radis of the epherical core, It

${ }^{R}(h)=$ position redius at a point in a horisontal leyer of ilquid at a helght, $h$, It $\mathrm{R}^{\mathrm{l}}(\mathrm{h})=\begin{aligned} & \text { radius of a circle cut by the chordel plane at a } \\ & \text { helght, } \mathrm{h}, \mathrm{ft}\end{aligned}$

$\Delta \mathrm{B}_{(\mathrm{h})}=$ Inerement of position realus, It

$\mathrm{Bv}$ - redius of the centrel gas vold, It -

Be - Reynolds number, $\frac{2 A_{b} \text { U } \rho_{2}}{\mu}$, dinensionless

$t=t 1 m e, \sec$

$V$ = veloeity of a moving partiole relative to the 11quid, It/sec .

$U_{\infty}=$ steady state velocity, $\mathrm{It} / \mathrm{sec}$

$\mathrm{J}_{(\mathrm{h})}=$ mean radial velocity of all gat bubbles noving in a layer of 11quid at a height, $\mathrm{h}, \mathrm{ft} / \mathrm{sec}$

$\nabla_{r}=$ radial velocity of the gas bubble relative to a rixed coordinate systea, $\mathrm{It} / \mathrm{sec}$

$u, v, v=x, y, z$ componente respectivily of the nutd veloulty, $f t / s e c$

$v_{r}=$ radial component of the liquid volocity, $\mathrm{ft} / \mathrm{eec}$

$v_{t}=$ tangential component of the 11quid velocity, rt/sec

$v_{b}=$ gas bubble volume, cu $2 t$

$v_{G}=$ volume of eas generated per unit timo per unit volumo of 11quid, $\sec ^{-1}$

$V_{H}=$ total volume of gas bubbles contalned in the spherical core, cu It

$x_{1}, x_{2}, X_{3}-x_{2}, y, 2$ colponents reapectively of any extraneous forces acting on a flusd elesent, pounds force/pound mase

$x, y, z=$ space coordinates, $\mathrm{ft}$ 


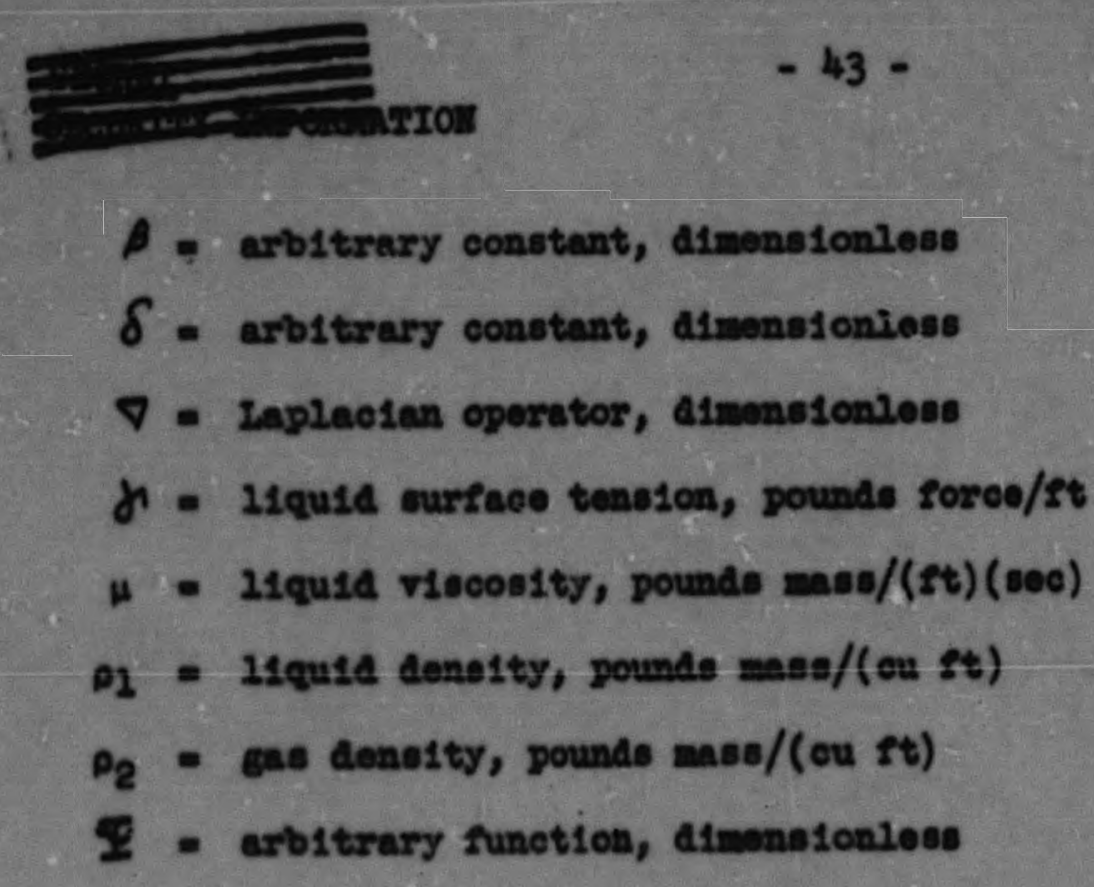

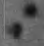

$+$

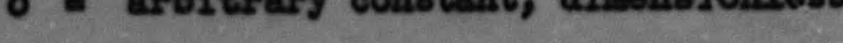

$\nabla=$ Laplecian operator, Almonsionlese

j. - Iiquid ourtace tenoion, pownds $20200 / 2 t$

$D_{1}=11$ qu1 dene1ty, pounde mase/(ou gt)

$P_{2}=$ gas density, pounds mase/(ou ft)

$\Psi$ - arbitrary funetion, aimonatonloes

$\cdot$

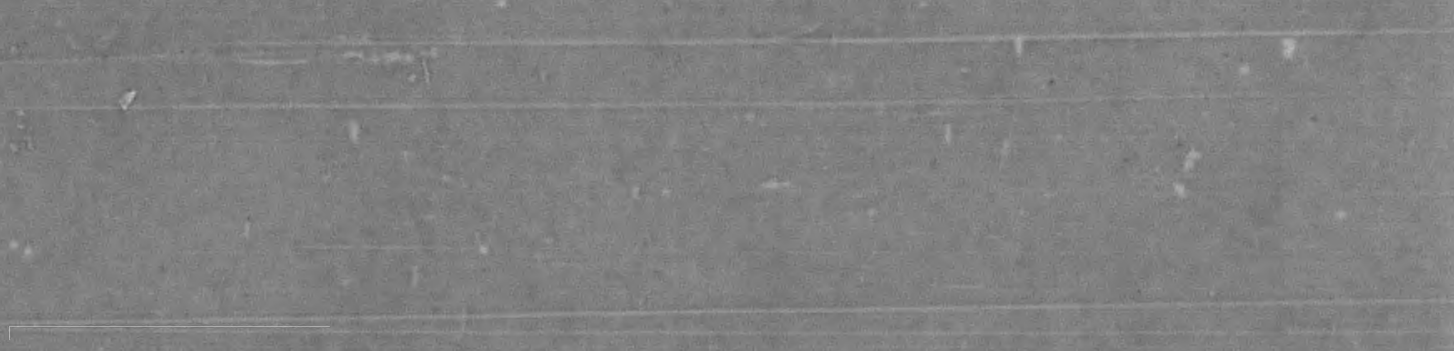




\section{APPIIDIX B}

\section{COMPUIATIOH PROCESURE}

1. Radial Velocity of A Gas Bubble in the BRB Core at $482^{\circ}$ \% (See Figure 5) For these conditions:

$$
\begin{aligned}
& P_{1}=51.0 \text { pounds mass } /(\text { cu } \mathrm{ft}) \\
& P_{2}=1.8 \text { pounds mass } /(\text { cu ft) } \\
& \mu=0.75 \times 10^{-4} \text { pounds mass } /(\mathrm{ft})(\mathrm{sec}) \\
& \gamma=2.33 \times 10^{-3} \text { pounds force } /(\mathrm{ft})
\end{aligned}
$$

For this particular conputation, assune:

$$
\begin{aligned}
& R_{b}=0.25 \mathrm{In} \cong 0.0208 \mathrm{ft} \\
& R=0.48 \mathrm{ft}
\end{aligned}
$$

Inlet P1pe Diameter = 2 in.

Using equation (2) and (2),

$$
\begin{aligned}
& v_{t}=4.8(0.48)^{-0.77}=8.43 \mathrm{ft} / \mathrm{sec} \\
& v_{x}=\frac{0.0177}{0.48\left(0.5625-0.48^{2}\right)^{1 / 2}}=0.06 \mathrm{rt} / \mathrm{sec}
\end{aligned}
$$

From the definition of $\mathrm{N}_{G}$,

$$
v_{0}=\frac{8 x 8.43^{2}(51.0-1.8)}{3 \times 0.48 \times 51.0}=381.1 \mathrm{ft} /(\mathrm{sec})^{2}
$$

By a trial and error procedure, it is found that equation (29a) applies to the computation of the bubble velocity under these conditions. Frms

$$
v=0.825\left[\frac{381.1^{4}}{32.17}\right]^{0.083}\left[\frac{2.33 \times 10^{-3} \times 32.17}{51.0}\right]^{0.250}=0.88 \mathrm{ft} / \mathrm{sec}
$$




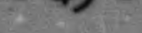

Then usirg equation (26),

$$
v_{r}=0.88+0.06=0.94 \mathrm{ft} / \mathrm{sec}
$$

These computations are then repeated for other values of the position radius, R. The results of such a serfes of calculations of this one size of gas bubble 18 shown in Figure 5.

\section{Naximum Cas Bubble Residence Time (Bee Figure 4)}

The maxtman gas bubble residence time is given by equation $(30)$ in the form of an Integral to be evaluated. This Integral may be evaluated Eraphically by using the results of computation (1) in a plot: of the form shoun below:

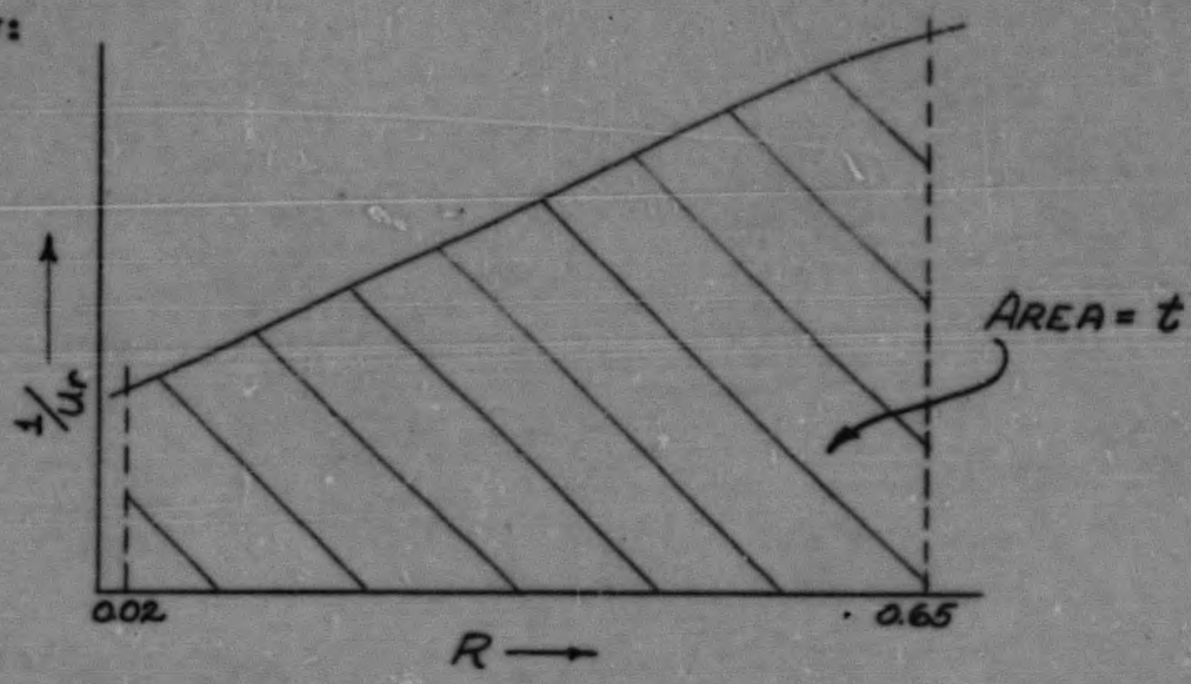

The grea under this curve is equal to the maximin gas bubble residence time. The results of such a procedure are show in Figure 4.

3. Total Gas Hold-Up in the HRs Core (See F1gure 6)

From equation $(40)$, the volume of gas contained in the core is given

by

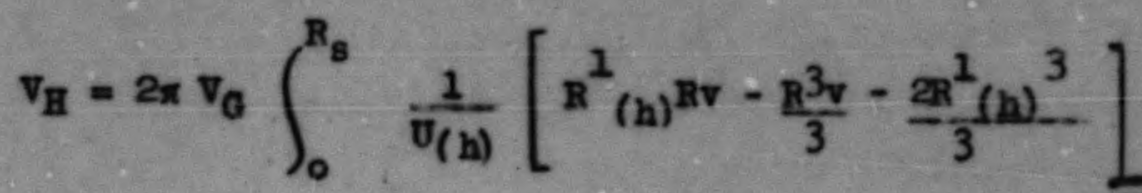




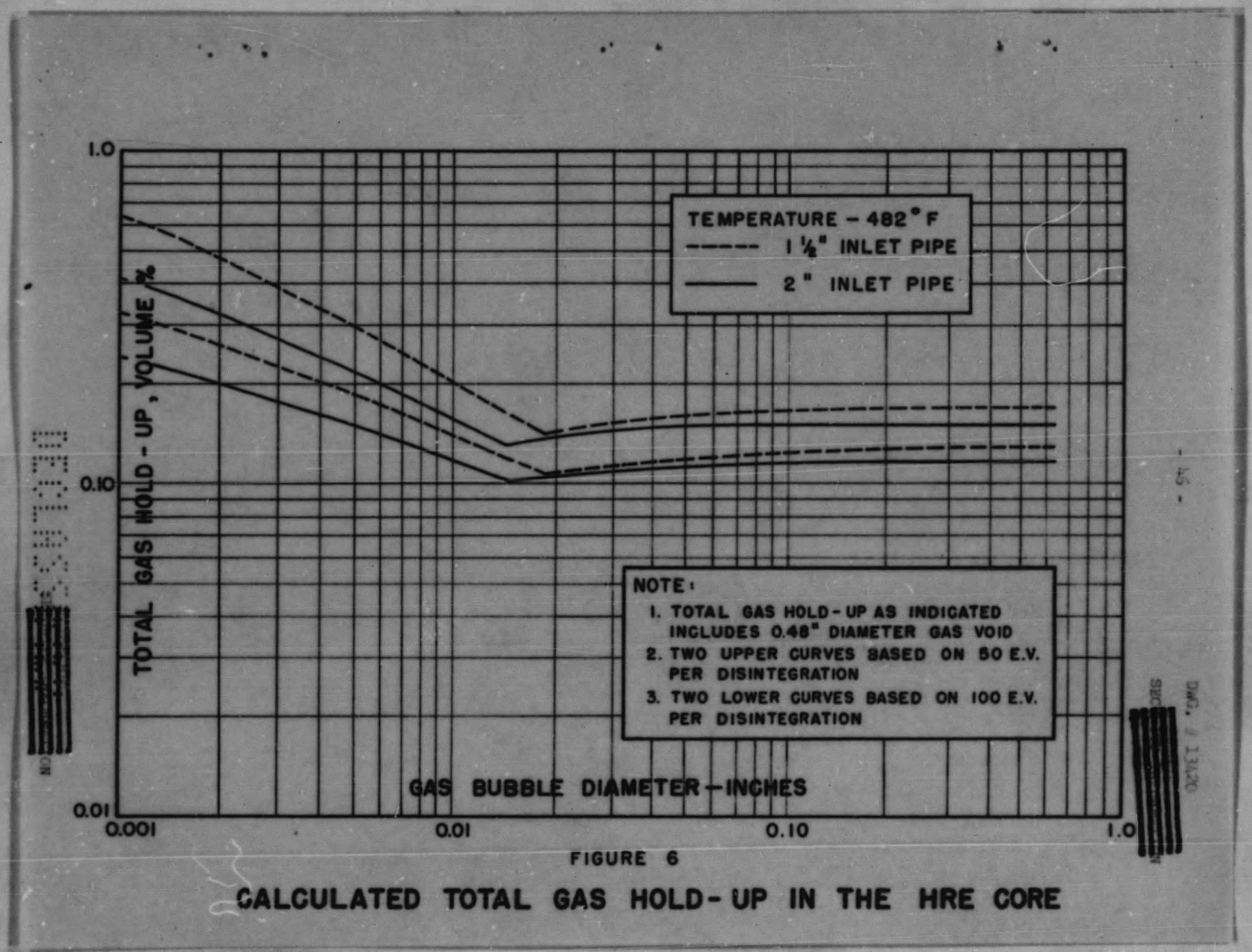




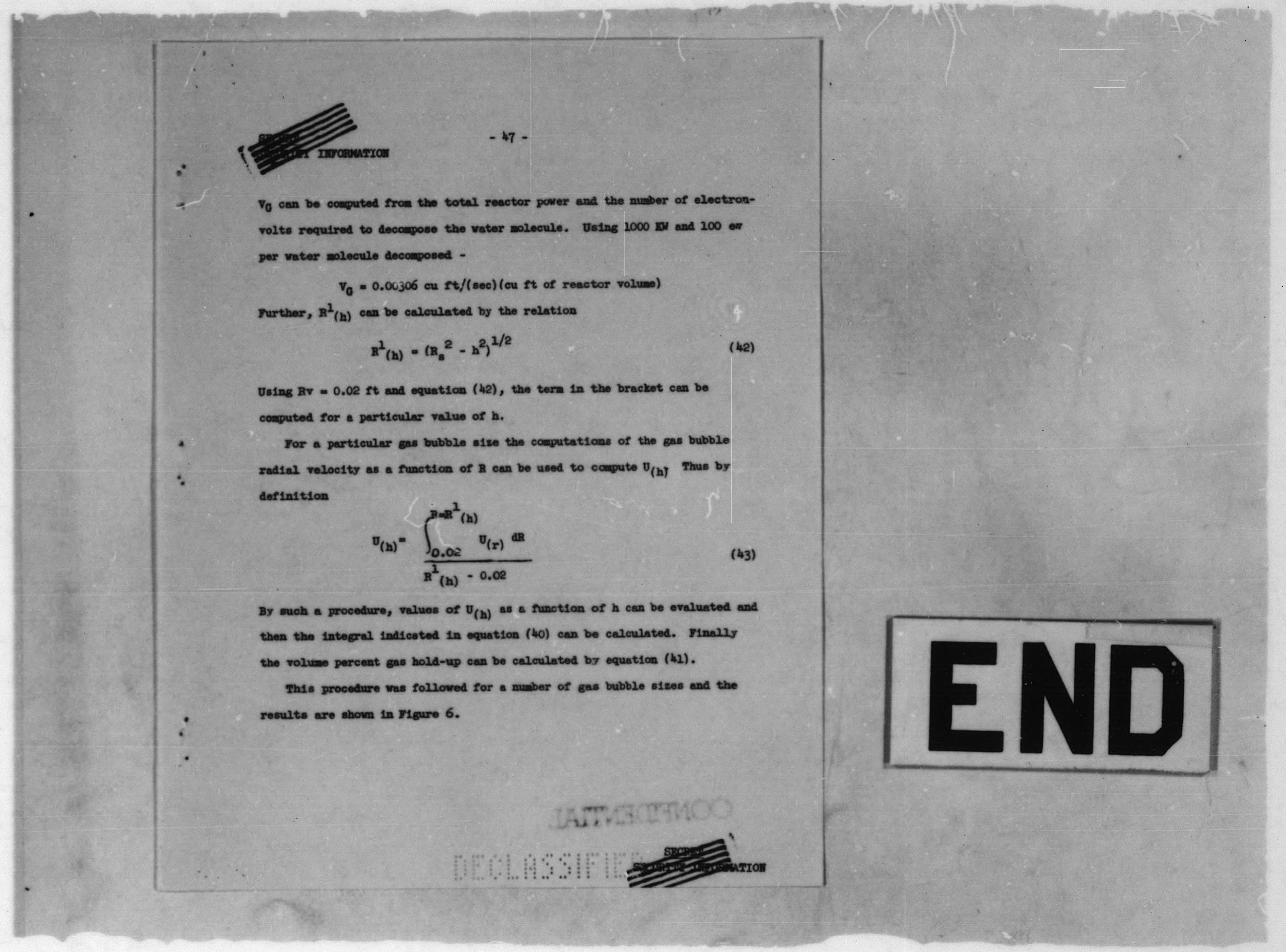

